Article

\title{
Practical Analysis and Design of a Battery Management System for a Grid-Connected DC Microgrid for the Reduction of the Tariff Cost and Battery Life Maximization
}

\author{
Robert Salas-Puente * (D), Silvia Marzal, Raul Gonzalez-Medina ${ }^{(D)}$, Emilio Figueres \\ and Gabriel Garcera (iD) \\ Grupo de Sistemas Electrónicos Industriales del Departamento de Ingeniería Electrónica, \\ Universitat Politècnica de València, Camino de Vera s/n, 46022 Valencia, Spain; silmarro@upv.es (S.M.); \\ raugonme@upv.es (R.G.-M.); efiguere@eln.upv.es (E.F.); ggarcera@eln.upv.es (G.G.) \\ * Correspondence: rosapue1@posgrado.upv.es; Tel.: +34-(96)-3877007 (ext. 76021)
}

Received: 5 June 2018; Accepted: 16 July 2018; Published: 19 July 2018

\begin{abstract}
This study is focused on two areas: the design of a Battery Energy Storage System (BESS) for a grid-connected DC Microgrid and the power management of that microgrid. The power management is performed by a Microgrid Central Controller (MGCC). A Microgrid operator provides daily information to the MGCC about the photovoltaic generation profile, the load demand profile, and the real-time prices of the electricity in order to plan the power interchange between the BESS and the main grid, establishing the desired state of charge (SOC) of the batteries at any time. The main goals of the power management strategy under study are to minimize the cost of the electricity that is imported from the grid and to maximize battery life by means of an adequate charging procedure, which sets the charging rate as a function of the MG state. Experimental and simulation results in many realistic scenarios demonstrate that the proposed methodology achieves a proper power management of the DC microgrid.
\end{abstract}

Keywords: DC microgrid; battery energy storage system; battery management system

\section{Introduction}

Nowadays, the increasing demand for electricity has encouraged the production of local energy by means of the integration of Microgrids (MGs) into the main grid [1]. The MGs are low power distribution systems which have distributed generation (DG), energy storage systems (ESSs) and a variety of loads. The DG is mainly composed by Renewable Energy Sources (RESs) such as PV systems, wind turbines, biomass, etc., whose intermittent nature produces strong power imbalances in the MG that can be compensated by the main grid or by the ESSs operating in the MG. A MG example is shown in Figure 1a, where the term PCC stands for the Point of Common Coupling with the main grid.

ESSs are a fundamental part of MGs, because they allow for a better utilization of the RESs, contributing to the MGs stability and reliability [1,2]. The DC microgrid under study in this work is depicted in Figure 1b. The Battery Energy Storage System (BESS) is formed of: (i) a battery bank, (ii) a Battery Management System (BMS) [3] and (iii) a DC/DC converter. It is important to point out that batteries are considered among the best energy storage devices, due to their quick technological evolution in smart grids and electric vehicles [4]. The essential characteristics of a battery are: the energy storage capacity, the efficiency, the lifetime (expressed in the number of cycles) and the operation temperature. The kind of batteries that are most commonly used in MGs for energy storage applications are Lead Acid (LA) or Valve regulated lead acid (VRLA) and lithium-ion (Li-ion) batteries [5-8]. In [6], a study was carried out on the most relevant characteristics in the selection process of the suitable 
battery technology for different applications. The main characteristics of the most widely used battery technologies in MGs are described in Table 1. LA batteries are widely used in MGs, because their implementation cost is the lowest among all usual technologies. In addition, this kind of batteries provides an acceptable performance and a great robustness. Nevertheless, their main drawback is their relatively short cycle life (1500-9000 charge/discharge cycles). On the contrary, Li-ion batteries have a long cycle life (>10,000 cycles) and their efficiency is approximately $95 \%$, but their implementation cost is high (>USD 350/kW.h) [9] Moreover, the BMS of Li-ion batteries is more complex than that of VRLA batteries, due to the need for inner cell protections against overcharges and cell voltage equalization circuits $[7,10,11]$.

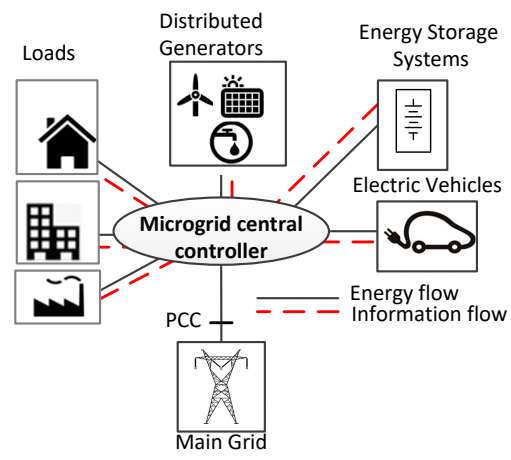

(a)

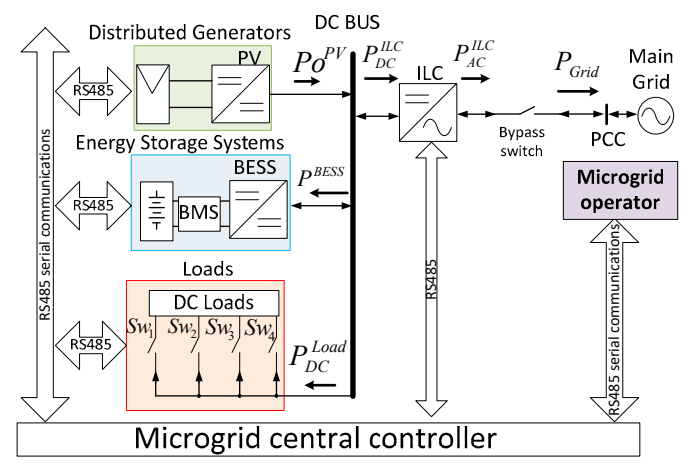

(b)

Figure 1. MG with central controller: (a) MG control system and intercommunication network; (b) DC Microgrid under study.

Table 1. Main characteristics of the most widely used battery technologies in MGs.

\begin{tabular}{cclcccc}
\hline Battery Type & $\begin{array}{c}\text { Power Rating } \\
\text { (MW) }\end{array}$ & Discharge Time & $\begin{array}{c}\text { Life Time } \\
\text { (Years) }\end{array}$ & $\begin{array}{c}\text { Cycle Life } \\
\text { (Cycles) }\end{array}$ & $\begin{array}{c}\text { Reliability and } \\
\text { Efficiency (\%) }\end{array}$ & $\begin{array}{c}\text { Cost } \\
\text { (USD/kW·h) }\end{array}$ \\
\hline $\begin{array}{c}\text { Flooded Lead } \\
\text { Acid, VRLA }\end{array}$ & $0-20$ & Seconds-hours & $5-15$ & $1500-9000$ & $70-90 \%$ & $180-300$ \\
\hline Lithium ion & $0-0.1$ & Minutes-hours & $5-15$ & $>10,000$ & Close to $100 \%$ & $350-1100$ \\
\hline
\end{tabular}

Regarding the power management in the MGs, one of the crucial challenges is to keep the power balance between the generation and the demand. The power imbalance is a common scenario in MGs, being caused by the discontinuity in the energy generation or by the changes in the power demand. Nowadays, adequate strategies have been developed to manage the power dispatch in the MGs, which can be: centralized, decentralized or distributed [12-21].

In the decentralized and distributed control strategies the power management and control are integrated in the local controllers of the DGs and ESSs, so that in the case of malfunction of any device, the MG can properly operate after the disconnection of the faulty unit. According to [1], some decentralized control strategies based on the droop method [20] do not need the implementation of a communications system and provide the plug and play function of DG units. Nevertheless, a communication system is necessary for monitoring the power dispatch in the MG so that the power dispatch can be optimized and the status of each power unit can be known [17]. The main limitation of distributed control strategies takes place in environments with large communication delays and measurement errors, which brings about problems in the convergence speed and stability margins of the controls $[1,17,18]$.

Centralized control eases the optimization of the power distribution in the MG by coordinating the power devices by means of a smart centralized system operating through a communication system. A Microgrid Central Controller (MGCC) acquires system data and sets the power to be managed by each of the converters under operation, broadcasting power references to all the power devices in the MG, such as DGs, loads, ESSs, etc. [21]. 
Centralized control is suitable for small-scale microgrids with a low number of DGs an ESSs [1,21]. In this paper a MGCC performs the power management algorithms which can run on microcontrollers which provide simple communications [22].

This study is focused on two areas: the design of a Battery Energy Storage System (BESS) for a grid-connected DC microgrid and the power management of that MG. The goals of the grid connected MGs power management have been studied in previous works [16-23]. For optimizing the management of the energy generation and consumption, data like electricity tariffs, weather forecast or energy demand are used [23]. Recently, price schemes have been used in the literature to optimize the economic benefits of producers and consumers [24-28]. An industrial application of optimal operating strategies was presented in [27]. In [24], an optimal management model for residential facilities with Vehicle-to-grid (V2G) systems was presented. In those management systems battery wear and energy costs were considered. In [25], a home power management system was proposed to minimize electricity cost and reduce high peak demand while maintaining user comfort. The algorithm that is presented in [28] finds an appropriate time of charging with low cost for electrical vehicles based on prediction of energy prices during the charging period. Most techniques optimize the power consumption over a single day, but in [27] a monthly bill was considered, for performing a multi-day optimization.

The main contribution of this work is the development of a power management strategy implemented in an MGCC for minimizing the cost of electricity in a grid connected DC microgrid and maximizing battery life. The MGCC receives from the MG operator the daily information about the prices of the electricity and the expected profiles of photovoltaic generation and load demand. The MGCC establishes the desired state of charge (SOC) in the BESS during the whole day. The proposed strategy takes advantage from the RESs and adjusts the battery energy storage through a suitable charging procedure. A BESS specially designed for DC microgrids is studied, whose BMS performs a charging procedure according to DIN 41773 [29,30] whenever it's possible. The BMS guarantees the proper operating conditions of the batteries, as specified by the manufacturer $[29,30]$. This approach maximizes the lifetime of the batteries and, consequently, minimizes the costs of their replacement [3,11]. The goal of the BMS is to charge the batteries with the excess of renewable generation and from the grid when the electricity tariff is low. If the SOC is below a certain minimum value and the renewable generation cannot charge the batteries alone, the extra power needed to charge the batteries will be imported from the grid with a value lower than or equal to the contracted power, no matter the electricity tariff. If the power which can be imported from the grid is enough to charge the batteries according to a DIN 41773 procedure, the batteries are charge accordingly. If not, the batteries are charged with a lower power.

This strategy allows to charge the batteries during off-peak hours, when $\mathrm{kW} \cdot \mathrm{h}$ is cheaper, and selling their energy to the main grid during peak hours. The charging rates and the available power for charging the batteries are adjusted based on a target SOC that is defined for several time intervals during a day, i.e., the BMS adjusts the charging rates based on the MG state. Furthermore, the modeling of the BESS by means of an accurate electrical second order model of the batteries is presented.

This paper consists of six sections. In Section 2 a brief overview of the Battery Management Systems is performed. Subsequently, a BESS specific design proposal for DC microgrids is described in Section 3. Then, all the concepts related to the proposed power management algorithm are explained in Section 4. Simulations and experimental results are described in Section 5. Finally, Section 6 draws the conclusions of this paper.

\section{Overview of Battery Management System in MGs}

The main goals of a BMS that allow for an adequate operation of the batteries and to extend their service life are: (i) to operate the batteries according to an adequate SOC; (ii) to control the maximum charging/discharging current and voltage [3], as specified by the manufacturer; and (iii) to set a proper depth of discharge (DOD) of the batteries [3-31]. In this work the maximum allowed value of the DOD is $65 \%$, which is slightly smaller than the maximum recommended value for VLRA batteries $(70 \%)$, which can be found in literature [8]. 
The BMS should implement an appropriate charge/discharge procedure of batteries that guarantees their operational conditions, as specified by the manufacturer. These procedures can be: charging batteries at constant current (CC) or constant voltage (CV). However, the RESs of the MGs may have power fluctuations that cause sudden variations in the available power for charging the batteries. Those sudden variations increase the BMS complexity and require the use of advanced techniques to manage the battery charging process [31-34]. In [32,33], some battery charging algorithms and their limitations have been reported. Other parameters that increase the BMS complexity are the kind of battery used and the estimation techniques of both the SOC and the state of life (SOL) [11]. Nevertheless, the battery life time is complex, because it depends on temperature variation, corrosion and maximum charge/discharge currents $[4,6]$, etc. A comparative summary about some BMSs reported in the literature for diverse applications is shown in Table 2.

The SOC represents the available charge that is stored in the battery compared with the rated capacity charge of the battery. The SOC cannot be directly measured from the batteries and it is used to determine the power that can be extracted from them. In the literature, different methods to estimate the SOC are presented: the Ampere-hour integral or Coulomb counting method [35], the open-circuit voltage method [36], the electrochemical impedance spectroscopy method [37], machine learning-based methods [38], kalman-filter based methods [39], sliding mode observer methods [40], and the adaptive-gain nonlinear observer method [41], among others. The first four methods do not need to establish the battery model, so that they are called Non-model based methods. These methods cannot correct errors caused by the SOC incorrect initialization and the external perturbations [42]. The BMS proposed in this work has the following subsystems:

- Battery monitoring: This subsystem includes voltage, current, impedance and temperature measurements. The monitoring allows for calculating the battery parameters: SOC, SOL, DOD and State of Health (SOH), yielding an estimation of the battery model. The $\mathrm{SOH}$ represents an estimation of the capacity of the battery to store and deliver energy, compared with a new battery [43]. The SOL is similar to the $\mathrm{SOH}$. However, the SOL is defined in literature as the remaining time until the battery needs to be replaced [11]. It is possible to estimate the SOL, saving the data corresponding to the DOD values and the temperatures at which the batteries have been exposed [44]. The BMS of this paper uses the $\mathrm{SOH}$ concept. In order to estimate the $\mathrm{SOH}$ of the batteries, some studies [35] consider the following expression: $\mathrm{SOH}(\%)=\left(\mathrm{Q}_{\mathrm{MAX}} / \mathrm{Q}_{\text {Rated }}\right)$ $100 \%$; where $Q_{\text {Rated }}$ is the rated capacity and $Q_{\text {MAX }}$ is the maximum releasable capacity when the battery is fully charged, which will decline with the used time.

- Battery protection: Protection can be implemented in both the hardware and the software. This includes protection and diagnosis in the following situations: high temperature, overcharge, overcurrent and the communication loss with the system.

- Battery control: This subsystem is responsible for the battery charging procedure. Its goal is to extend the service time of batteries and to allow for a proper energy management in the system.

- Communication system: This subsystem informs a central controller about the parameters of the batteries in order to manage the power dispatch of the MG. These communications allow for an interface with the user and the interaction with the power management in the MG.

In this paper, the design of a BESS for a DC microgrid is presented. The BESS is based on a BMS that optimizes the energy storage and implements an adequate charge procedure, which changes the charging rate and plans the SOC of the battery depending on the MG scenarios. The BMS has all the elements summarized in Table 2 [45-59]. A battery electrical model is described, which allows for determining all the static and dynamic characteristics of the battery. This model is necessary to design the control loops of the power converter of the BESS taking into account all the involved variables. Overall, the batteries can be approximated to a voltage source in series with RC elements (Resistor-Capacitor), where each one represents a specific dynamics for every charging condition $[41,60,61]$. 
Table 2. Comparative table of some battery charging systems.

\begin{tabular}{|c|c|c|c|c|c|c|c|c|c|c|c|}
\hline \multicolumn{12}{|c|}{ Battery Management System } \\
\hline \multirow{2}{*}{\multicolumn{3}{|c|}{ Monitoring }} & \multicolumn{4}{|c|}{ Protection } & \multirow{2}{*}{\multicolumn{2}{|c|}{ Control }} & \multirow{4}{*}{$\begin{array}{c}\text { Communication } \\
\text { System }\end{array}$} & \multicolumn{2}{|l|}{ Applications } \\
\hline & & & \multirow{3}{*}{ 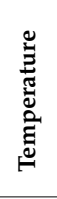 } & \multirow{3}{*}{ 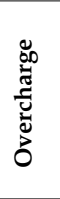 } & \multirow{3}{*}{ 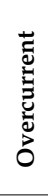 } & \multirow{3}{*}{ 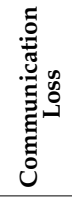 } & & & & & \\
\hline \multirow{2}{*}{$\begin{array}{l}\text { Battery } \\
\text { Model }\end{array}$} & \multicolumn{2}{|c|}{ Estimation } & & & & & \multirow{2}{*}{$\begin{array}{l}\text { Thermal } \\
\text { Management }\end{array}$} & \multirow{2}{*}{ Optimization } & & & 可 \\
\hline & SOC & SOH & & & & & & & & & $\approx$ \\
\hline - (1) $^{(1)}$ & $\bullet$ & - & - & - & - & - & - & - & $\bullet$ & $\begin{array}{l}\text { Uninterruptible } \\
\text { power supplies }\end{array}$ & [45] \\
\hline$\bullet$ & $\bullet$ & - & - & $\bullet$ & $\bullet$ & $\bullet$ & $\bullet$ & $\bullet$ & $\bullet$ & DC Microgrid & [46] \\
\hline- & - & - & $\bullet$ & • & • & • & - & - & $\bullet$ & $\begin{array}{l}\text { Uninterruptible } \\
\text { power supplies }\end{array}$ & [47] \\
\hline- & $\bullet$ & - & $\bullet$ & • & $\bullet$ & - & • & $\bullet$ & - & $\begin{array}{c}\text { Portable electronic } \\
\text { devices }\end{array}$ & [48] \\
\hline$\bullet$ & - & $\bullet$ & - & • & $\bullet$ & - & - & - & - & $\begin{array}{l}\text { Motorcycles, cars, } \\
\text { wheelchairs, UPS }\end{array}$ & [49] \\
\hline- & - & - & $\bullet$ & • & • & - & - & - & • & $\begin{array}{c}\text { Portable } \\
\text { electronics devices }\end{array}$ & [50] \\
\hline- & - & $\bullet$ & $\bullet$ & • & • & - & $\bullet$ & • & • & $\begin{array}{c}\text { Portable } \\
\text { electronics devices }\end{array}$ & [51] \\
\hline- & $\bullet$ & $\bullet$ & $\bullet$ & • & • & - & $\bullet$ & $\bullet$ & - & $\begin{array}{l}\text { Hybrid electric } \\
\text { vehicles }\end{array}$ & [52] \\
\hline- & - & - & $\bullet$ & • & $\bullet$ & - & $\bullet$ & $\bullet$ & • & $\begin{array}{l}\text { Portable } \\
\text { applications }\end{array}$ & [53] \\
\hline$\bullet$ & $\bullet$ & - & - & $\bullet$ & $\bullet$ & - & $\bullet$ & $\bullet$ & $\bullet$ & DC Microgrid & [54] \\
\hline- & $\bullet$ & - & $\bullet$ & $\bullet$ & $\bullet$ & - & - & - & - & Electric vehicles & [55] \\
\hline- & - & - & - & $\bullet$ & $\bullet$ & - & $\bullet$ & $\bullet$ & - & $\begin{array}{l}\text { Motorcycles, cars, } \\
\text { wheelchairs }\end{array}$ & [56] \\
\hline$\bullet$ & $\bullet$ & - & $\bullet$ & $\bullet$ & $\bullet$ & - & - & - & - & $\begin{array}{c}\text { Photovoltaic } \\
\text { systems }\end{array}$ & [57] \\
\hline- & $\bullet$ & - & - & • & $\bullet$ & - & - & - & - & $\begin{array}{l}\text { Hybrid electric } \\
\text { vehicles and } \\
\text { Electric vehicles }\end{array}$ & [58] \\
\hline- & • & - & $\bullet$ & $\bullet$ & $\bullet$ & - & - & - & - & $\begin{array}{c}\text { Photovoltaic } \\
\text { systems }\end{array}$ & [59] \\
\hline
\end{tabular}

\section{Design of the Battery Energy Storage System}

The BESS keeps the power balance at the DC bus of the MG. The BESS is composed by: (i) a battery bank, (ii) a BMS and (iii) a DC/DC converter. In this Section, all the power conversion processes have been modeled. The battery model, the BMS and a description of the converter control are shown in the following Subsections.

\subsection{Selection of the Battery Bank}

The capacity of the battery bank is selected to fulfill the following criteria: (i) batteries can be discharged if the available power on the DC bus is lower than that necessary at the MG or when the electricity tariff is high; (ii) batteries must be charged during off-peak times with the surplus of energy which is available from the RES if there is such a surplus. If not, some power from the main grid will be imported for charging the batteries; (iii) the batteries initial cost must be low. However, there's a trade-off between saving money from the electricity tariff, which requires a big battery bank, and obtaining a low cost of the battery system. In order to make both of the goals compatible, a low cost battery technology has been chosen. Furthermore, a value of the DOD (DOD $=65 \%$ ) close to the maximum recommended $[8,29]$ one has been aimed in the proposed BMS, in order to get a reasonable size of the battery bank. For this study, the power profile of the photovoltaic generation $\left(P_{P r o f i l e}^{P V}\right)$, 
the power consumed by the loads $\left(P_{D C_{C} \text { Lrofile }}^{\text {Lod }}\right)$ and the tariff costs according to the time of use (TOU) of electricity are taken as reference. This is shown in Figure 2a.

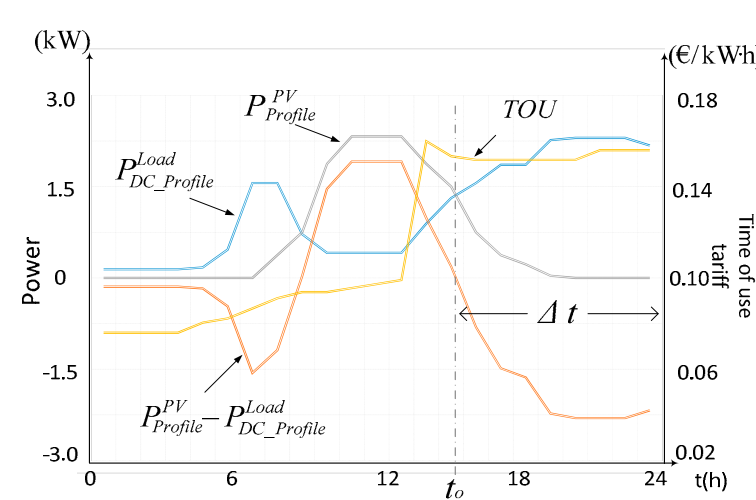

(a)

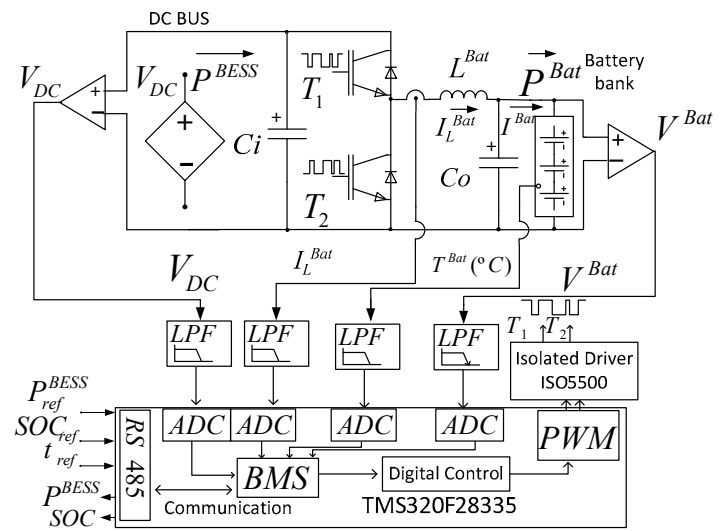

(b)

Figure 2. Battery Energy Storage System (BESS): (a) Reference profiles of PV generation $\left(P_{P r o f i l e}^{P V}\right)$, power consumed by the loads $\left(P_{D C_{-}}^{\text {Load }}\right.$ Profile $)$ and time of use (TOU) tariff of electricity in the MG; (b) Electrical diagram of the BESS.

The PV generation decreases from 16:00 $\mathrm{h}$ to 19:00 $\mathrm{h}$, as can be seen in Figure 2a. At this time, the power demand is higher than PV generation and the TOU price is on peak. At this point, the batteries should have stored enough energy to fulfill the power demand of the MG. Equations (1) and (2) allow for determining the number of batteries that is needed to accomplish this last objective. In (1) and (2), $P_{\text {Avaailable }}^{\text {Bat }}$ stands for the available power that the batteries should supply during a time interval $\Delta t$, supposing that they have been fully charged to a value SOC $>95 \%$ before. The time instant when the battery discharge interval starts is called $\mathrm{t}_{\mathrm{o}} . V_{\text {Selected }}^{\text {Batter }}$ is the rated voltage of the battery.

In this work, a VRLA battery has been selected, model: SUN POWER VRM 12V105 (HOPPECKE, Brilon, Germany). Its characteristics are shown in Table 3 [62]. As it can be seen in Figure 2a, the average power consumed by the load from $16: 00 \mathrm{~h}$ to $24: 00 \mathrm{~h}\left(t_{0}=16 \mathrm{~h}, \Delta t=8 \mathrm{~h}\right)$ is $2.7 \mathrm{~kW}$ and this average power should be provided by the batteries. $P_{\text {Available }}^{\text {Bat }} \cong 2.7 \mathrm{~kW}$ during that time interval, $\Delta t$. The number of batteries of the battery bank is obtained from Equation (2). It is composed of 18 batteries of $12 \mathrm{~V}$ connected in series, with a battery bank rated voltage of $V_{\text {Rated }}^{\text {Bat }}=216 \mathrm{~V}$. The battery bank is charged/discharged from/to the DC bus of the MG by means of a $3 \mathrm{~kW}$ bidirectional half-bridge DC/DC converter, as shown in Figure 2b. The LC output filter of the DC/DC converter has an inductance value, $L^{\text {Bat }}$, which has been calculated taking into consideration: (i) the maximum ripple current allowed by the batteries, and (ii) the ripple current through $L^{B a t}, \Delta I_{L}^{B a t}$, should guarantee the continuous current conduction mode if the current is higher than $10 \%$ of the maximum current. The value of $L^{B a t}$ is calculated from Equation (3), where $V_{D C}$ is the DC bus voltage and $F_{s w}$ is the switching frequency of the converter [49]. The values of the input and output capacitances, $\mathrm{Ci}$ and $\mathrm{Co}$, can be calculated from (4) and (5), respectively.

$$
\begin{gathered}
P_{\text {Available }}^{\text {Bat }}=\frac{1}{\Delta t \cdot \mathrm{DOD}} \cdot \int_{t_{o}}^{t_{0}+\Delta t}\left(P_{\text {Profile }}^{\text {PV }}-P_{\text {DC__Profile }}^{\text {Load }}\right) \cdot d t \\
\text { Number } \\
L^{\text {Batteries }}=\frac{\left|P_{\text {Available }}^{\text {Bat }}\right| \cdot \Delta t}{Q_{\text {Rated }} \cdot V_{\text {Selected }}^{\text {Battery }}} \\
\frac{V_{\text {Rated }}^{\text {Bat }}}{4 \cdot \Delta I_{L}^{\text {Bat }} \cdot F_{S W}}
\end{gathered}
$$




$$
\begin{gathered}
C i \geq \frac{P_{\text {HB-Rated }}^{\text {BESS }}}{2 \cdot V_{D C} \cdot \Delta V_{D C} \cdot F_{S W}} \\
C o \geq \frac{I_{\text {Max }}^{\text {Bat }}}{2 \cdot \Delta V_{\text {Max }}^{\text {Bat }} \cdot F_{S W}}
\end{gathered}
$$

\begin{tabular}{|c|c|c|}
\hline \multirow{2}{*}{ DC/DC Converter } & Battery Specifications & \multirow{2}{*}{$\begin{array}{l}\text { Battery Bank Parameters } \\
\text { for Complying DIN } 41773\end{array}$} \\
\hline & Sun Power VRM 12V105 & \\
\hline$P_{\text {HB_Rated }}^{B E S S}=3 \mathrm{~kW}$ & $V_{\text {Selected }}^{\text {Battery }}=12 \mathrm{~V}$ & $-10^{\circ} \mathrm{C}<\mathrm{T}^{\text {Bat }}<45^{\circ} \mathrm{C}$ \\
\hline$F_{s w}=16 \mathrm{kHz}$ & $I_{M A X}^{B a t}=20 \mathrm{~A}$ & $V_{M i n}^{B a t}=194 \mathrm{~V}$ \\
\hline$C_{i}=1 \mathrm{mF}$ & $V_{\text {Rated }}^{\text {Bat }}=216 \mathrm{~V}$ & $V_{M A X}^{B a t}=260 \mathrm{~V}$ \\
\hline$C_{o}=1 \mathrm{mF}$ & $Q_{\text {Rated }}=105 \mathrm{~A} \cdot \mathrm{h}$ & $I_{\text {tail }}^{\text {Bat }}=1 \mathrm{~A}$ \\
\hline$L^{B a t}=5.4 \mathrm{mH}$ & $Q_{100}=101 \mathrm{~A} \cdot \mathrm{h}$ & $t_{C h}^{\text {tall }}<48 \mathrm{~h}$ \\
\hline$\eta_{B E S S}=0.97$ & $\Delta V_{M A X}^{\text {Bat }}=0.02 \cdot V_{\text {Rated }}^{\text {Bat }}$ & $I_{C 5} \cong 20 \mathrm{~A}$ \\
\hline $\begin{array}{c}V_{D C}=400 \mathrm{~V} \pm \Delta V_{D C} \\
\Delta V_{D C}=20 \mathrm{~V}\end{array}$ & $\begin{array}{c}\Delta I_{L}^{B a t}=0.1 \cdot I_{M A X}^{B a t} \\
\mathrm{DOD}=65 \%\end{array}$ & $I_{C 20} \cong 5 \mathrm{~A}$ \\
\hline
\end{tabular}

Table 3. BESS specifications.

\subsection{Modeling of Battery Bank}

The electric model of the battery bank used in this study is similar to that developed in [61], being shown in Figure 3. It has an open-circuit voltage source depending on the SOC, $V_{O C V}^{B a t}(\mathrm{SOC})$, connected in series with a resistor and a second-order R-C circuit that represents the transient response of battery. The impedance of the battery bank is represented by Equation (6) and the battery voltage by Equation (7).

$$
\begin{gathered}
Z^{\text {Bat }}(s)=R_{\text {Serie }}^{\text {Bat }}+\frac{R_{\text {Fast }}^{\text {Transient }}}{s \cdot R_{\text {Fast }}^{\text {Transient }} \cdot C_{\text {Fast }}^{\text {Transient }}+1}+\frac{R_{\text {Slow }}^{\text {Transient }}}{s \cdot R_{\text {Slow }}^{\text {Transient }} \cdot C_{\text {Slow }}^{\text {Transient }}+1} \\
V^{\text {Bat }}(s)=V_{\text {OCV }}^{\text {Bat }}(\mathrm{SOC})-I^{\text {Bat }} \cdot Z^{\text {Bat }}(s)
\end{gathered}
$$

The electric parameters of the chosen VRLA battery bank are shown by Equations (8) to (13) and have been obtained with an identical procedure to that shown in [60,61]. Those Equations are valid for SOC $>0.1$. Taking into account that SOC in this work is kept higher or equal than 0.35 , Equations (8) to (13) are valid in this study.

$$
\begin{gathered}
V_{\text {OCV }}^{\text {Bat }}(\mathrm{SOC})=202.52+16.29 \cdot \mathrm{SOC}-6.36 \cdot \mathrm{SOC}^{2}+24.19 \cdot \mathrm{SOC}^{3}-55.67 \cdot e^{-35 \cdot \mathrm{SOC}} \\
R_{\text {Serie }}^{\text {Bat }}=8.4348 \cdot e^{-24.37 \cdot \mathrm{SOC}}+2.0208 \\
R_{\text {Fast }}^{\text {Transient }}=17.3232 \cdot e^{-29.14 \cdot \mathrm{SOC}}+2.5212 \\
C_{\text {Fast }}^{\text {Transient }}=-14.1278 \cdot e^{-13.51 \cdot \mathrm{SOC}}+13.0296 \\
R_{\text {Slow }}^{\text {Transient }}=356.562 \cdot e^{-155.2 \cdot \mathrm{SOC}}+2.6913 \\
C_{\text {Slow }}^{\text {Transient }}=-112.1481 \cdot e^{-13.51 \cdot \mathrm{SOC}}+82.8704
\end{gathered}
$$




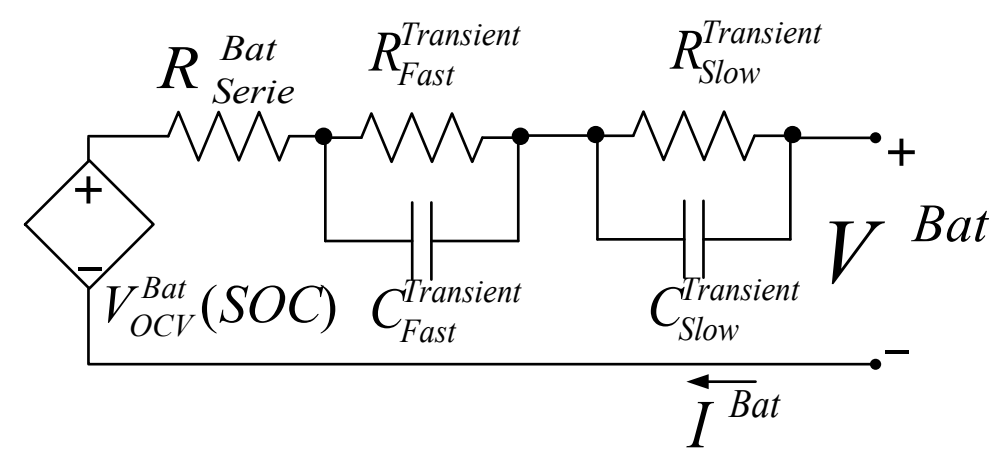

Figure 3. Second order model of the battery bank.

\subsection{Small-Signal Model of the BESS}

The small-signal model of the bidirectional half-bridge DC/DC converter is shown in Figure 4. That model has been derived from an averaged model where any electrical value $\mathrm{x}$ has a static term at the operation point, $X$, and a small-signal dynamic term, $\widetilde{x}$, being: $x=X+\widetilde{x}$. When the batteries are being charged with a charge current $I_{L(C h)}^{B a t}$, the converter works as a Buck converter, as depicted in Figure $4 \mathrm{a}$. When the batteries are being discharged with a discharge current $I_{L(D i s)}^{B a t}$, the converter works as a Boost converter, see Figure $4 \mathrm{~b}$. The transfer functions in Equations (14) and (15) are obtained from Figure 4 . They are used to design the controllers in charge mode (Ch) or discharge mode (Dis) of the battery bank.

$$
\begin{aligned}
& \frac{\left.\widetilde{i}_{L(C h / D i s)}^{B a t}(s)\right|_{\widetilde{v}_{D C}=\widetilde{v}_{O C V(S O C)}^{B a t}=0}}{\widetilde{d}}=\frac{V_{D C}}{s \cdot L^{B a t}+\frac{1}{s \cdot C o+\frac{1}{Z^{B a t}(s)}}} \\
& \left.\frac{\widetilde{v}^{B a t}}{\widetilde{i}_{L(C h)}^{B a t}}(s)\right|_{\widetilde{v}_{D C}=\widetilde{v}_{O C V}^{B a t}(S O C)=0}=\frac{1}{s \cdot C o+\frac{1}{Z^{B a t}(s)}}
\end{aligned}
$$

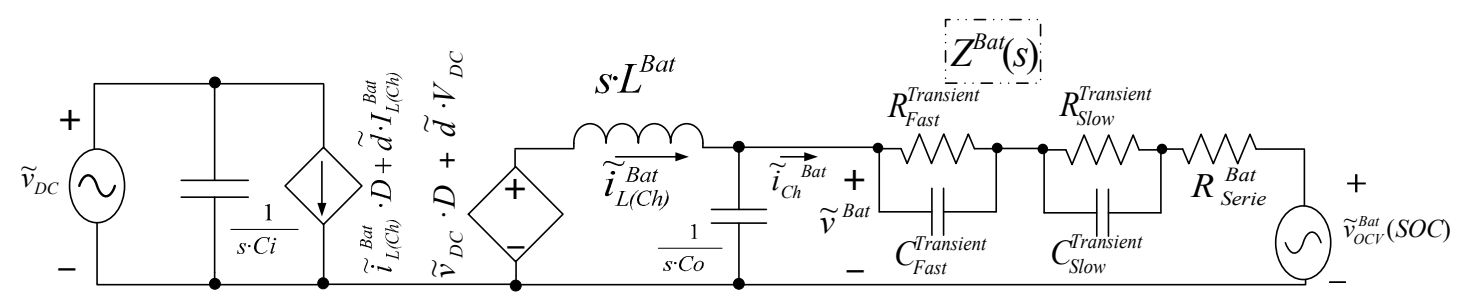

(a)

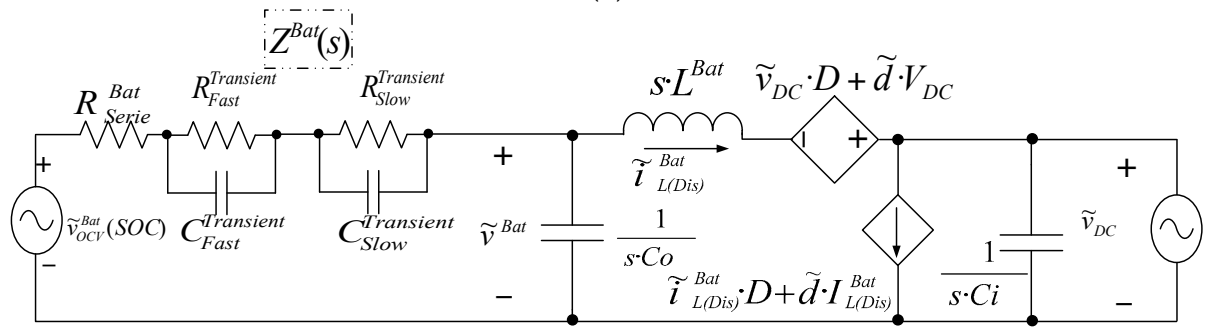

(b)

Figure 4. Small-signal model of the half-bridge DC/DC converter: (a) Buck small-signal model, charge mode (Ch); (b) Boost small-signal model, discharge mode (Dis). 


\subsection{Control Loops Design of the BESS}

The BESS works from a BMS that sets either the charge of the batteries at constant current (CC) or constant voltage (CV), or the discharge of the batteries at a constant current. The block diagram of the current control loop and of the voltage control loop of the BESS are shown in Figure 5. $G_{I L}^{B a t}(s)$ and $G_{V}^{B a t}(s)$ blocks represent, respectively, the transfer functions of the current and voltage regulators. $F m$ is the gain of the PWM modulator. $T_{I L(C h / D i s)}^{B a t}(s)$ is the transfer function of the open loop gain of the current loop, either in charge (Ch) or in discharge (Dis) mode. $T_{V}^{B a t}(s)$ is the transfer function of the open loop gain of the voltage loop in battery charge mode.

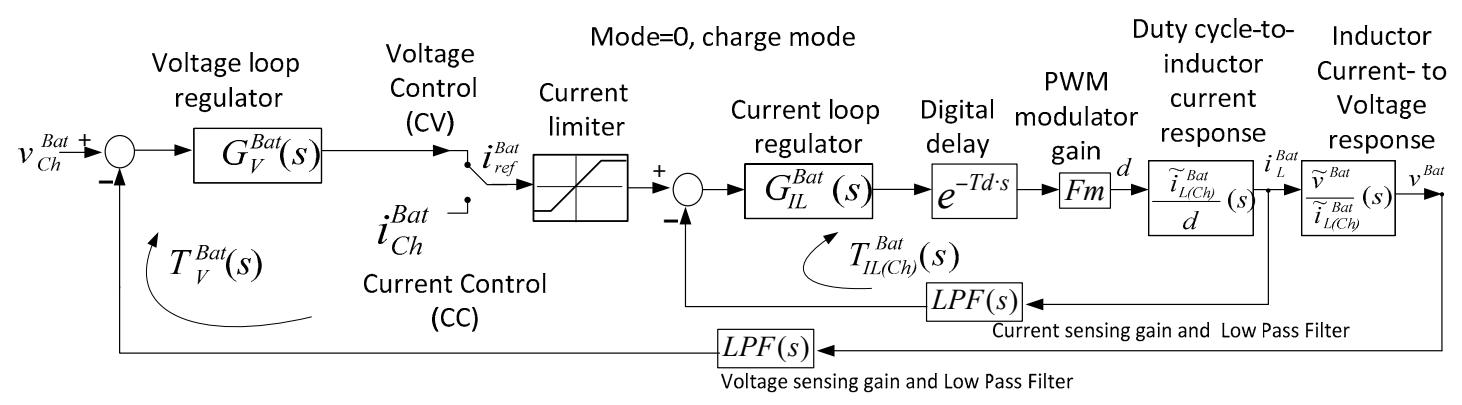

(a)

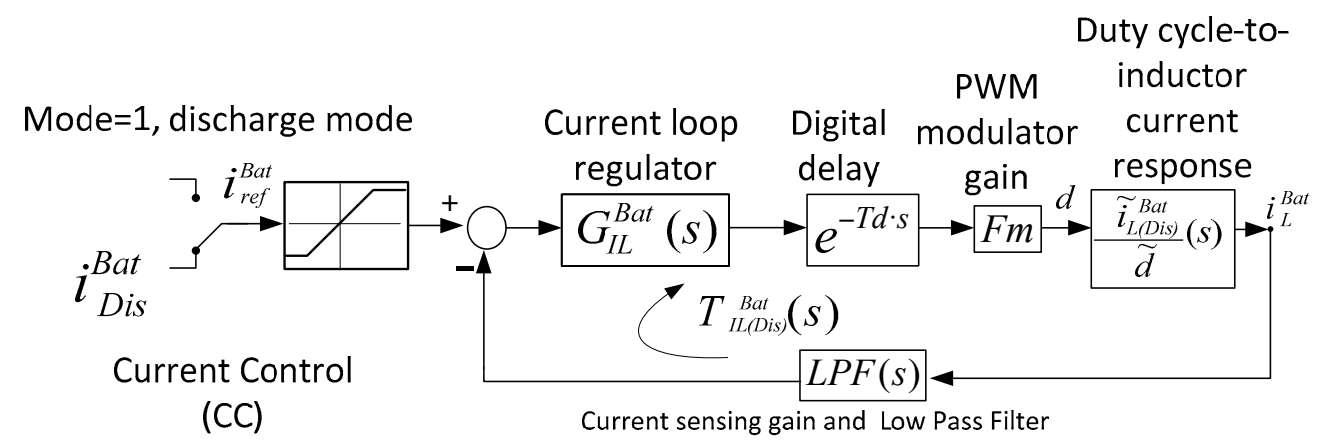

(b)

Figure 5. Control structure of the current control loop and of the voltage control loop of the batteries:

(a) Charge Mode and (b) Discharge Mode.

The Bode plots of the current loop $T_{I L(C h / D i s)}^{B a t}(s)$ for different values of the DC-bus voltage, $V_{D C}$, are shown in Figure 6a. The controller was designed in the analog domain, taking into account a digital delay of a sampling period, $T_{d}=T_{\text {samp }}$, and discretized in the $Z$ domain by using the Tustin transformation. The sampling frequency was $F_{\text {samp }}=16 \mathrm{kHz}=1 / T_{\text {samp }}$, which agrees with the switching frequency, $F_{S w}$. The current regulator, $G_{I L}^{B a t}(s)$, is adjusted to get a crossover frequency of the current loop: $F_{c i}=500 \mathrm{~Hz}<F_{S w} / 20$, with a phase margin around $60 \mathrm{deg}$. The Bode plots of the voltage loop, $T_{V}^{\text {Bat }}(s)$, for different values of the SOC are shown in Figure $6 \mathrm{~b}$. The voltage regulator $G_{V}^{\text {Bat }}(s)$ has been adjusted to get a crossover frequency of the voltage loop: $F_{c v}=12.6 \mathrm{~Hz}<F_{c i} / 20$, with a phase margin around $90 \mathrm{deg}$. The transfer functions of the regulators are summarized in Table 4. The BESS control loops are robust to any change in the battery charge/discharge currents, SOC, battery voltage and changes of the DC bus voltage, because the battery model is practically constant when the SOC is higher than $10 \%$, which is a suitable working range for the batteries. 


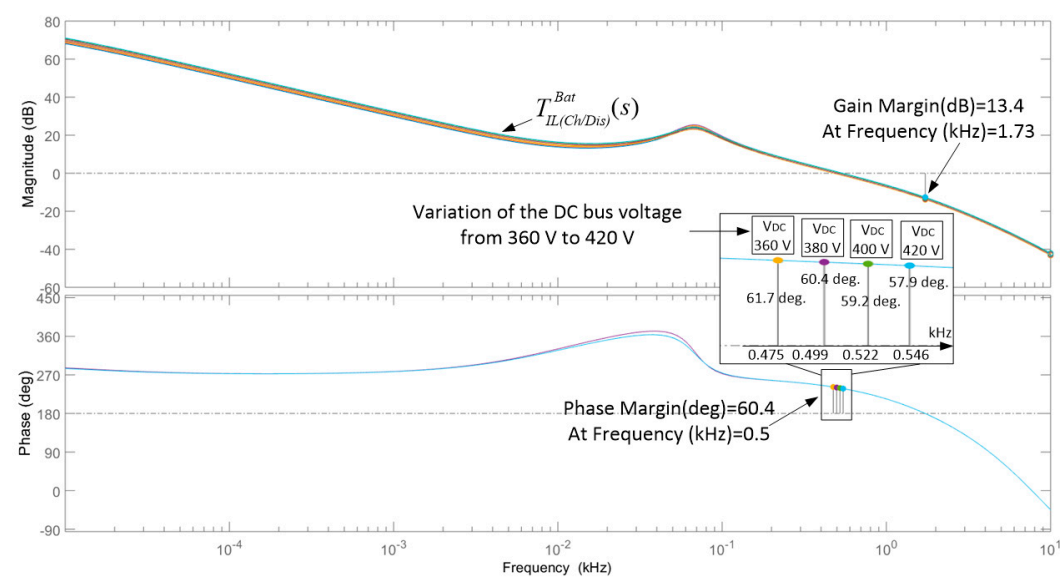

(a)

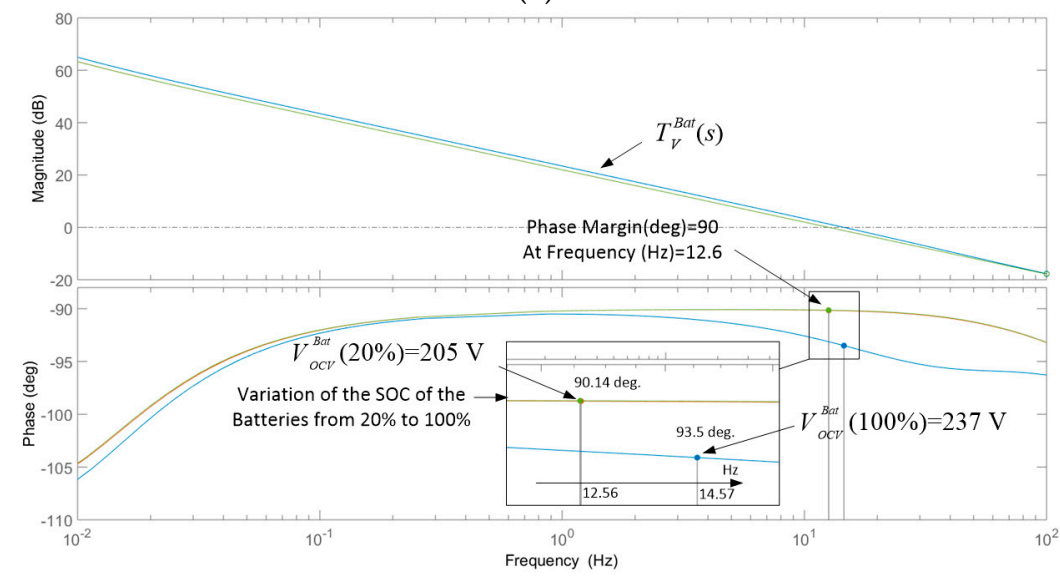

(b)

Figure 6. Bode plots of the loop gains: (a) Current loop for different values of the DC-bus voltage and (b) Voltage loop for different values of the SOC.

Table 4. Transfer functions of the BESS controllers and loop gains.

\begin{tabular}{|c|c|}
\hline Description & Transfer Function \\
\hline Low Pass Filter & $L P F(s)=\frac{1}{1.09 \cdot 10^{-9} \cdot s^{2}+9.91 \cdot 10^{-5} \cdot s+1}$ \\
\hline PWM Modulator gain & $F m=\frac{1}{\nabla_{\mathrm{PP}}}=1$ \\
\hline Battery Current-loop regulator & $G_{I I}^{\text {Bat }}(s)=\frac{0.0453 \cdot(1+s \cdot 0.018)}{s \cdot 0.018}$ \\
\hline Battery Voltage-loop regulator & $G_{V}^{\text {Bat }}(s)=\frac{0.0806 \cdot(1+s \cdot 0.0041)}{s \cdot 0.0041}$ \\
\hline Current Charge/Discharge-loop gain & $T_{I L(C h / D i s)}^{B a t}(s)=G_{I L}^{B a t}(s) \cdot \mathrm{e}^{-\mathrm{Td} \cdot s} \cdot F m \cdot \frac{\tilde{i}_{L(C h / D i s)}^{B a t}}{\mathrm{~d}}(s) \cdot L P F(s)$ \\
\hline Voltage-loop gain & $T_{V}^{B a t}(s)=G_{V}^{B a t}(s) \cdot \frac{T_{I L(C h / D i s)}^{B a t}(s)}{T_{I L(C h / D i s)}^{B a t}(s) \cdot L P F(s)+1} \cdot \frac{\widetilde{v}^{B a t}}{\tilde{i}_{L(C h)}^{B a t}}(s) \cdot \operatorname{LPF}(s)$ \\
\hline
\end{tabular}

\subsection{Design of the BMS}

The BMS is designed to fulfill the following objectives: (i) To broadcast the SOC of the batteries to the MGCC (ii) To coordinate the charging/discharging of the batteries depending on the power management strategies that are established by the MGCC and (iii) To adjust the parameters of the battery charge procedure depending on the MG state. The proposed BMS structure for the DC microgrid is shown in Figure 7.

The BMS has the following subsystems: 
- Battery Monitoring: It measures the battery parameters: current, voltage and temperature of the battery bank $\left(I^{\text {Bat }}, V^{\text {Bat }} y T^{\text {Bat }}\right)$. The initial SOC, DOD and SOH are estimated. A data table is stored corresponding to the amount of charge/discharge cycles, the battery model and its initial impedance.

- Battery Protection: The batteries are protected against overcharge, overcurrent, high temperature, communication loss and connection loss. The BMS sets the maximum charging/discharging current, the advisable SOC, the battery voltage and the maximum temperature.

- Battery Communication: The communication allows for the optimization of the battery charging/discharging process. In charge mode, the MGCC sends to the BESS information about the available power to charge batteries $\left(P_{r e f}^{B E S S}\right)$ and the time $\left(t_{r e f}\right)$ in which the BESS keeps this power. In addition, the MGCC sends the desired SOC $\left(S O C_{\text {ref }}\right)$ of the batteries, to be reached in a time $t_{\text {ref }}$. The BESS informs the MGCC about the current SOC and the absorbed/injected power from/to the DC bus by the BESS.

- Battery control: The current/voltage vs. time curves of the charge procedure of the battery bank are shown on the right side of Figure 7. First, the batteries are charged to a constant current (CC) until a maximum charging voltage is reached. At this point, the control is changed to constant voltage $(\mathrm{CV})$ in the batteries. The procedure is based on adjusting the current and voltage charging parameters of the batteries as a function of the MG state and complying with the DIN 41773 specifications [29] at the same time. The charge procedure is done by adjusting the battery current and voltage according to the temperature of the batteries and to the available power at the DC bus. In addition, the batteries can be charged or discharged depending on the cost of the electricity tariff and on the power availability at the RESs of the MG.

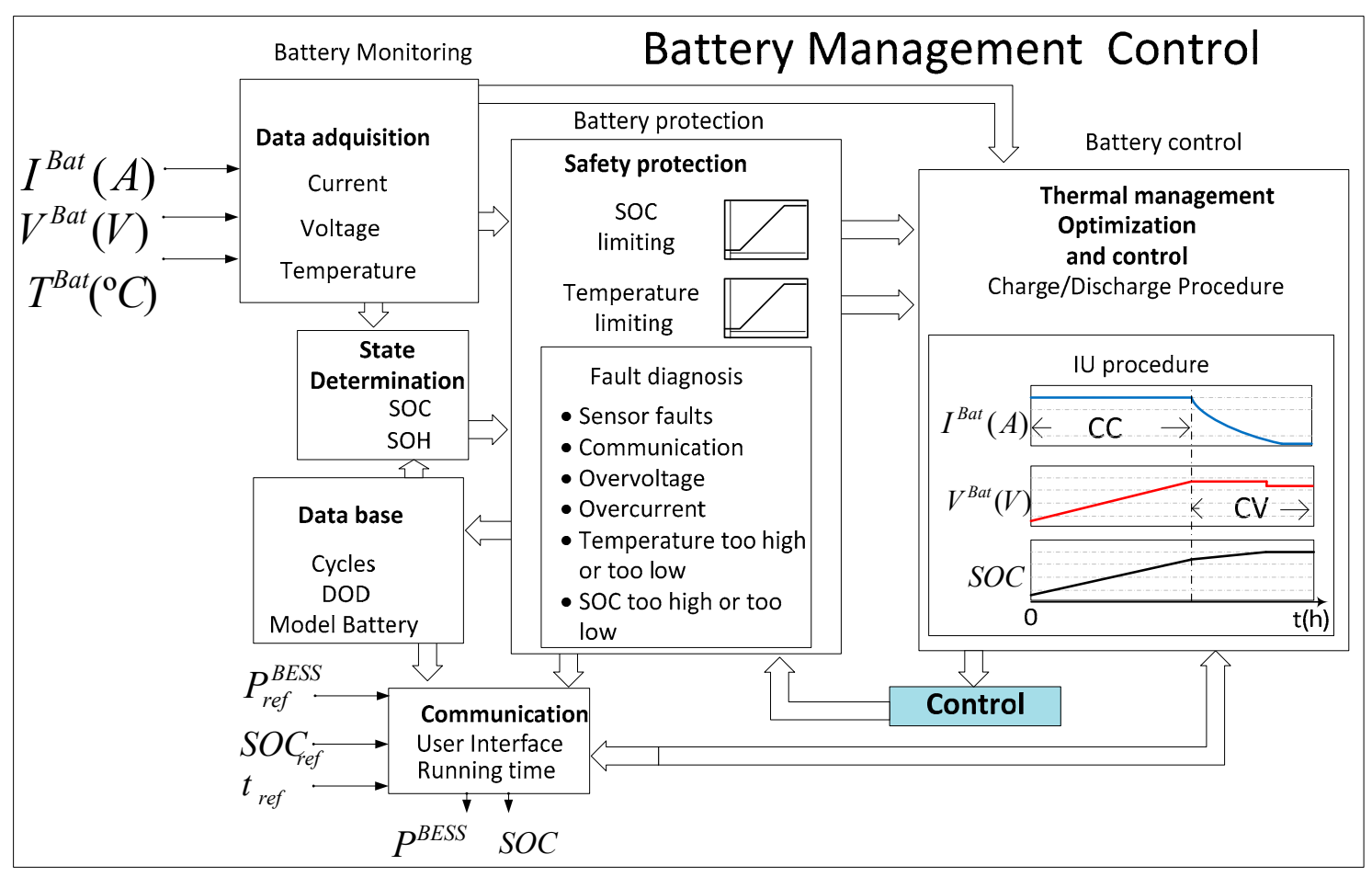

Figure 7. Proposed Battery Management System.

Battery Management Algorithm:

The battery management algorithm implemented in the BMS is shown in Figure 8 and it is described in the following. 


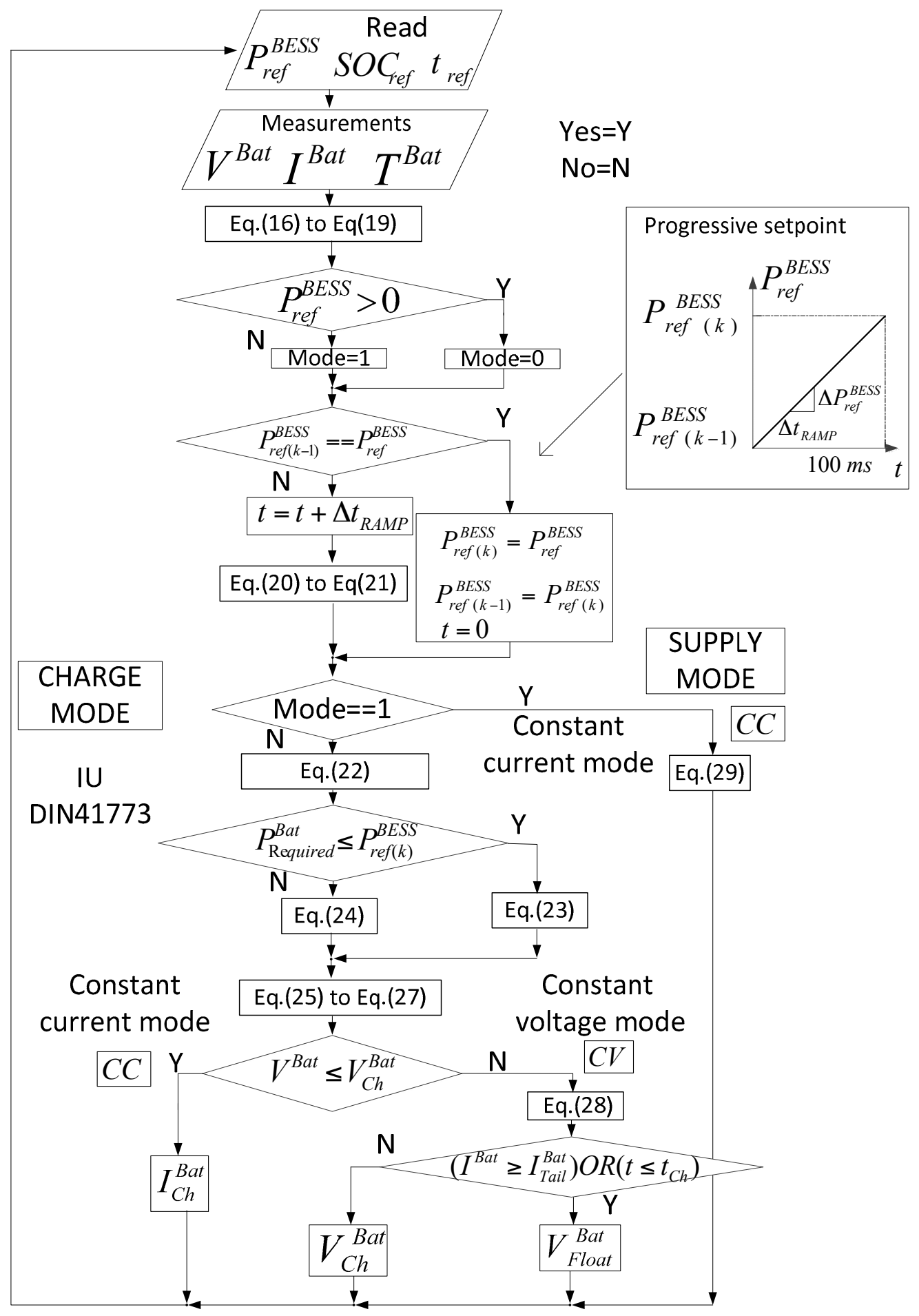

Figure 8. Battery charging algorithm.

The BMS receives three control parameters from the MGCC through RS485 serial communications. These parameters are: (i) the target $\mathrm{SOC}\left(S O C_{r e f}\right)$; (ii) the available/necessary power for discharging/charging the batteries $\left(P_{r e f}^{B E S S}\right)$ to/from the DC bus; and (iii) the time interval $t_{r e f}$, during which the BESS must reach $S O C_{r e f}$ with the available power at the DC bus. 
The BMS has three inputs that are produced by sensors: the signals from the battery current sensor, from the battery voltage sensor and from the battery temperature sensor, corresponding to $\mathrm{I}^{\mathrm{Bat}}$, $\mathrm{V}^{\text {Bat }}$ and $\mathrm{T}^{\mathrm{Bat}}$, respectively.

The SOC of the batteries can be calculated from Equation (16), where a positive (negative) value of $I^{\text {Bat }}$ represents a charging (discharging) current of the battery bank. $Q_{\text {Rated }}$ stands for the rated battery bank capacity in A.h. $Q_{\text {Dis(Ch) }}$, expressed by Equation (17), is the expected dis (charge) capacity in A.h, which depends on the dis (charge) rate. $\eta_{D i s(C h)}$ is the dis (charge) efficiency [10]. The value of $Q_{D i s(C h)}$ can be obtained by means of a linear interpolation of the curves of the battery capacity provided by the manufacturer [62].

$$
\begin{gathered}
\operatorname{SOC}(t)=\operatorname{SOC}(0)+\eta_{\text {Dis }} \cdot \int_{0}^{t} \frac{I^{\text {Bat }}(t)}{Q_{\text {Rated }}} \cdot d t \text { where } \eta_{\text {Dis }(C h)}=\frac{Q_{\text {Dis }(C h)}}{Q_{\text {Rated }}} \\
Q_{\text {Dis }}=104.6654-1.6456 \cdot\left|I^{\text {Bat }}\right|
\end{gathered}
$$

The battery bank charge power is given by the Equation (18) and the power absorbed by the BESS from the DC bus is represented by (19).

$$
\begin{aligned}
& P^{B a t}=I^{B a t} \cdot V^{B a t} \\
& P^{B E S S}=\frac{P^{B a t}}{\eta_{B E S S}}
\end{aligned}
$$

Taking into account that $P_{\text {ref }}^{B E S S}$ stands for the power setpoint to charge the batteries sent by the MGCC to the BESS, the operating mode of the BESS is set as follows: If $P_{B E E S \_r e f}>0$, the BESS will work in charge mode ('Mode $=0^{\prime}$ ), otherwise, the BESS will operate in discharge mode ('Mode $=1^{\prime}$ ).

Note from Figure 8 that there is a ramp function expressed by Equation (20) that changes the value of $P_{r e f}^{B E S S}$ inside the BESS, $P_{r e f(k)}^{B E S S}$, progressively from an initial value $P_{r e f(k-1)}^{B E S S}$ until it reaches the value $P_{r e f}^{B E S S}$ set by the MGCC, so that soft power transitions are performed. $P_{r e f(k)}^{B E S S}$ can be expressed by Equation (21). In (20) and (21), the variable " $t$ " represents the time, while " $k$ " represents the index of the last calculated sample of the power reference. When the value of $k$ increases from $(k-1)$ to $\mathrm{k}$, the resulting time step is $100 \mathrm{~ms}$. During the $100 \mathrm{~ms}$ span, 100 different intermediate values of the power reference are used to ramp between $P_{r e f(k-1)}^{B E S S}$ and $P_{r e f(k)}^{B E S S}$ each intermediate value is kept during $1 \mathrm{~ms}\left(\triangle t_{R A M P}\right)$. Other stepsize values are possible, but the chosen values have provided good practical results. Thus, the BESS avoids fluctuations in the DC bus due to abrupt bidirectional changes in the power setpoint, $P_{r e f}^{B E S S}$.

$$
\begin{aligned}
r(t) & =\frac{t}{100 \cdot \Delta t_{R A M P}},(0 \leq t \leq 100 \mathrm{~ms}) \\
P_{r e f(k)}^{B E S S} & =P_{r e f(k-1)}^{B E S S}+\left(P_{r e f}^{B E S S}-P_{r e f(k-1)}^{B E S S}\right) \cdot r(t)
\end{aligned}
$$

If 'Mode $=1$ ' (discharge mode). On the contrary, if 'Mode $=0$ ', the BMS calculates the power required $\left(P_{\text {Required }}^{\text {Bat }}\right)$ to reach the target SOC in the time interval $t_{\text {ref. }} . P_{\text {Required }}^{\text {Bat }}$ is given by Equation (22).

The charging procedure DIN41773 is carried out. The batteries are charged at CC until a maximum charging voltage is reached. If $P_{\text {Required }}^{\text {Bat }}<P_{r e f(k)}^{B E S S}$, the batteries will be charged with current $I_{(\mathrm{Ch})}^{\text {Bat }}$ calculated from Equation (23) and the $S O C_{r e f}$ will be reached in the specified time $t_{\text {ref. }}$ Otherwise, the batteries will be charged with a current $I_{(\mathrm{Ch})}^{B a t}$ given by Equation (24) and the $S O C_{r e f}$ will not be reached in the desired time, because the current available power is not enough.

When the maximum charging voltage $V_{(\mathrm{Ch})}^{\mathrm{Bat}}$ is reached, the batteries are charged at constant voltage. The value of $V_{(\mathrm{Ch})}^{\mathrm{Bat}}$ depends both on the temperature and on the charging current of batteries. The current dependence, $V_{(\mathrm{Ch})}^{\mathrm{Bat}}\left(I_{(\mathrm{Ch})}^{\text {Bat }}\right)$, and the temperature dependence, $V_{(\mathrm{Ch})}^{\text {Bat }}\left(T^{\mathrm{Bat}}\right)$, are shown by Equations (25) and (26), respectively. Equation (25) provides $V_{(\mathrm{Ch})}^{\mathrm{Bat}}$ for charging the battery at a given current according to 
the charge procedure that was recommended by the manufacturer [62]. The recommended value of $V_{(\mathrm{C} h)}^{\mathrm{Bat}}$ may be lower because of the battery temperature (26). Finally, the value of $V_{(C h)}^{B a t}$ is given by Equation (27). The minimum and maximum values of the charging current suggested by the manufacturer of the chosen batteries are: $\mathrm{I}_{\mathrm{C} 20}=5$ A and $\mathrm{I}_{\mathrm{C} 5}=20 \mathrm{~A}$, being $\mathrm{C} 20$ and $\mathrm{C} 5$ the specified battery capacity (measured in $\mathrm{A} \cdot \mathrm{h}$ ) for a discharge time of $20 \mathrm{~h}$ and $5 \mathrm{~h}$, respectively.

$$
\begin{aligned}
& P_{\text {Required }}^{\text {Bat }}=\frac{\left(S O C_{r e f}-S O C\right) \cdot Q_{\text {Rated }} \cdot V_{\text {Rated }}^{\text {Bat }}}{100 \% \cdot t_{\text {ref }} \cdot \eta_{\text {Dis }}} \text { where } S O C_{\text {ref }}>S O C \\
& I_{C h}^{\text {Bat }}=\operatorname{MIN}\left[\frac{P_{\text {HB-Rated }}^{\text {BESS }} \cdot \eta_{B E S S}}{V_{\text {Rated }}^{\text {Bat }}}, \frac{P_{\text {Required }}^{\text {Bat }}}{V_{\text {Rated }}^{\text {Bat }}}\right] \\
& I_{C h}^{\text {Bat }}=\operatorname{MIN}\left[\frac{P_{\text {HB-Rated }}^{\text {BESS }} \cdot \eta_{B E S S}}{V_{\text {Rated }}^{\text {Bat }}}, \frac{P_{\text {ref }(k)}^{B E S S} \cdot \eta_{B E S S}}{V_{\text {Rated }}^{\text {Bat }}}\right] \\
& V_{C h}^{B a t}\left(I_{C h}^{B a t}\right)=\frac{\left(V_{M a x}^{B a t}-V_{M i n}^{B a t}\right) \cdot I_{C h}^{B a t}}{I_{C 5}-I_{C 20}}+249.2 V \\
& V_{C h}^{\text {Bat }}\left(T^{\text {Bat }}\right)=267.7-\left(0.49 \cdot T^{\text {Bat }}+3.8 \cdot T^{\text {Bat2 }}-0.67 \cdot T^{\text {Bat3 }}+0.01 \cdot T^{\text {Bat } 4}\right) \cdot 10^{-3} \\
& V_{C h}^{B a t}=\operatorname{MIN}\left[V_{C h}^{\text {Bat }}\left(I_{C h}^{B a t}\right), V_{C h}^{\text {Bat }}\left(T^{\text {Bat }}\right)\right]
\end{aligned}
$$

Once the current that was absorbed by the batteries is lower than a pre-set tail current $\left(I_{\text {tail }}^{\text {Bat }}\right)$ or after a certain charging time $\left(t_{C h}\right)$ has elapsed, the battery voltage is kept at a floating voltage value $\left(V_{\text {Float }}^{\text {Bat }}\right)$ that is expressed by Equation (28). This Equation is obtained from the polynomial interpolation of the floating voltage curves which were provided by the manufacturer [62]. It can be observed that the value of $V_{\text {Float }}^{\text {Bat }}$ depends on the battery temperature.

$$
V_{\text {Float }}^{\text {Bat }}\left(T^{\text {Bat }}\right)=253.5-\left(0.62 \cdot T^{\text {Bat }}-3.1 \cdot T^{\text {Bat } 2}+0.41 \cdot T^{\text {Bat } 3}\right) \cdot 10^{-3}
$$

If 'Mode $=1$ ' (discharge mode), the BESS operation switches to discharge mode and the discharge current is calculated from Equation (29).

$$
I_{\text {Dis }}^{\text {Bat }}=-M I N\left[\frac{P_{\text {HB-Rated }}^{\text {BESS }}}{\eta_{B E S S} \cdot V_{\text {Rated }}^{\text {Bat }}}, \frac{\left|P_{\text {ref }}^{\text {BESS }}(k)\right|}{\eta_{B E S S} \cdot V_{\text {Rated }}^{\text {Bat }}}\right]
$$

\section{Centralized Power Management Algorithm of the DC Microgrid Tied to the Main Grid}

In this Section a centralized power management algorithm for the grid-connected DC Microgrid is described. The DC microgrid consists of: (a) a MGCC; (b) an interlinking converter (ILC) connected to the main grid which regulates the DC bus voltage; (c) two DC/DC converters operating as controlled current sources interchanging their power with the DC bus; (d) four DC loads with their respective electronic switches; (e) an RS485 serial communication system and (f) the MG operator. Figure 9a depicts the placement of the power converters operating in the DC microgrid.

The MGCC receives the information from the MG operator about of the prices of the electricity, of the photovoltaic generation and of the load demand. The MGCC extracts the minimum possible power from the grid to the MG to reduce the electricity bill. If there is an excess of available power at the PV generation and if the SOC of the batteries is adequate, the surplus power can be injected from the MG to the grid under the limit which was determined by the MG operator. As a last resort, the MGCC depending on the SOC, can implement a load shedding functionality to decrease the power which is absorbed from the grid and avoid the batteries undercharging. 
The Power Management Algorithm of the MG

The parameters broadcasted among the power converters, MG operator and the MGCC are shown in Table 5. The MGCC establishes the daily planning of the power dispatch in the MG, depending on the reference profiles sent by the MG operator to the MGCC. The evolution in time during a day of the reference profiles $\left(P_{\text {Profile, }}^{P V}, P_{D C_{-} \text {Proafile }}^{\text {Load }} P_{G \text { Gid-to-MG }}^{M A X} P_{M G-t o-G r i d}^{M A X}\right.$ and TOU) is shown in Figure $9 \mathrm{~b} . P_{\text {Profile }}^{P V}$ is the PV power profile, $P_{D C_{-} P r o f i l e}^{L}$ is the profile of the power consumed by the DC loads. $P_{G r i d-t o-M G}^{M A X}$ is the maximum power that can be imported from the grid to the MG and $P_{M G-t o-G r i d}^{M A X}$ is the maximum power that can be exported from the MG to the grid.

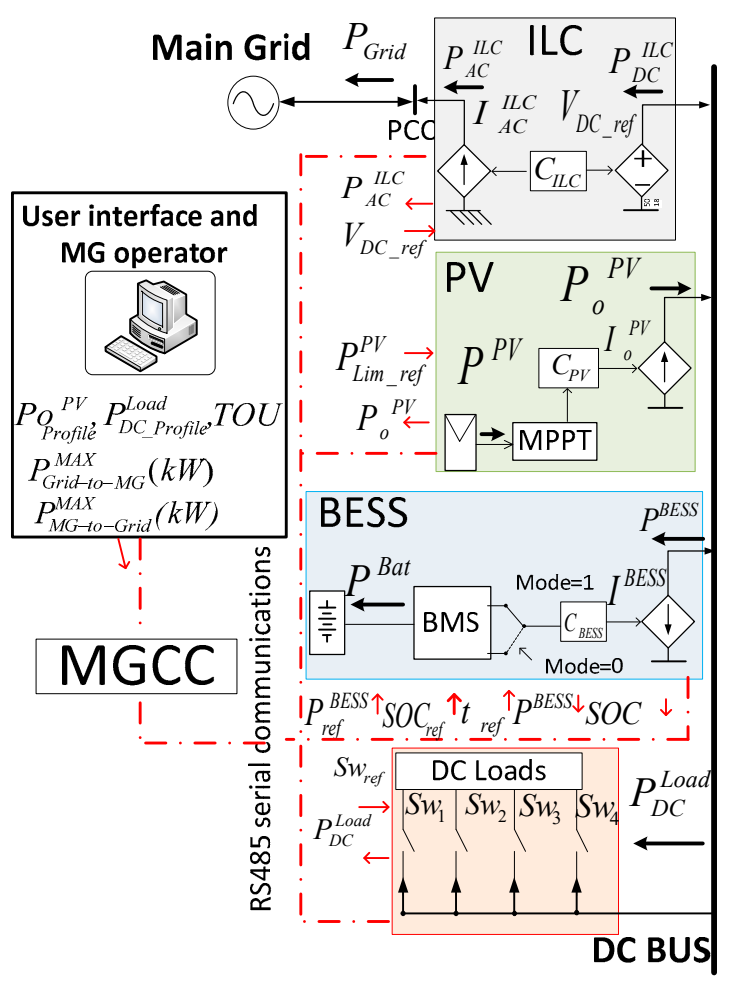

(a)
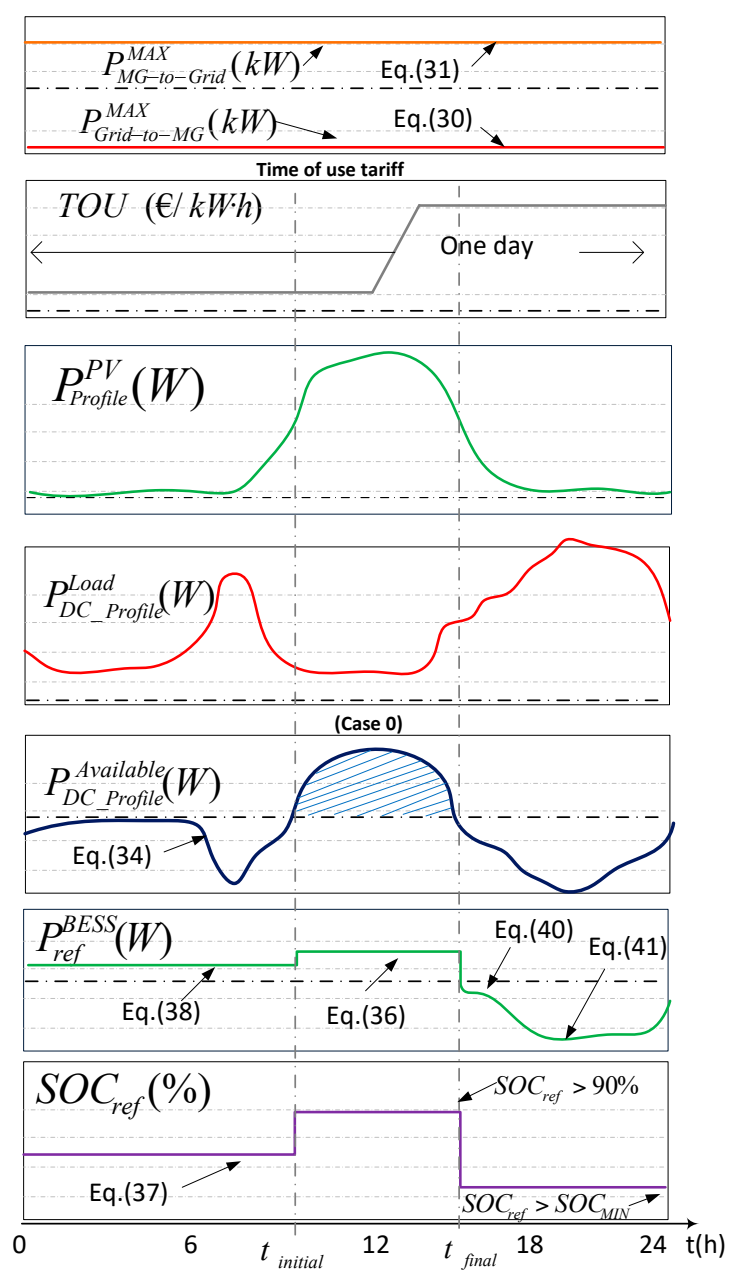

(b)

Figure 9. DC microgrid implemented: (a) Placement of the power converters operating in the DC microgrid; (b) Graphics of the power profiles and of the charge process of the batteries (Case 0 ). 
Table 5. Parameters broadcasted between the power converters of the DC microgrid and the MGCC.

\begin{tabular}{|c|c|c|c|c|c|}
\hline \multirow{2}{*}{ MGCC } & \multirow{2}{*}{ MG Operator } & \multicolumn{4}{|c|}{ Power Converters } \\
\hline & & ILC & BESS & PV & DC Load \\
\hline $\begin{array}{l}\text { Output } \\
\text { reference values }\end{array}$ & & $V_{D C_{-} r e f}$ & $\begin{array}{c}P_{r e f}^{B E S S} \\
S O C_{r e f} t_{r e f}\end{array}$ & $P_{\text {Lim_ref }}^{P V}$ & $\begin{array}{c}S w w_{r e f}=\left\{S w 1_{r e f},\right. \\
\left.S w 2_{r e f}, S w 3_{r e f}, S w 4_{r e f}\right\}\end{array}$ \\
\hline \multirow[b]{2}{*}{ Input } & Reference Profiles & \multicolumn{4}{|c|}{ Input measurement ${ }^{(2)}$} \\
\hline & $\begin{array}{l}P_{G r i d-t o-M G^{\prime}}^{M A X} \\
P_{M G-t o-G r i d}^{M A X} \\
\text { TOU, PV Profile' } \\
P_{\text {Do__Profile }}^{\text {Load }}\end{array}$ & $P_{\text {Grid }}$ & $\begin{array}{c}S O C \\
P^{B E S S}\end{array}$ & $P_{O}^{P V}$ & $P_{\text {Load }}^{D C}$ \\
\hline
\end{tabular}

The power management algorithm of the MG is shown in Figure 10 and it is executed every $1 \mathrm{~s}(1 \mathrm{~Hz})$, performing the request of the measurements of $P^{B E S S}, P_{L o a d}^{D C}, P_{o}^{P V}, P_{A C}^{I L C}$ and SOC, and transmitting the references to the MG devices. The MGCC selects one of six possible power management cases during the whole day and calculates the reference values, which are transmitted to all the power converters under operation. The cases depend on the scenarios of the MG and are summarized in Table 6. The daily power management is carried out according to the following time intervals:

$0<$ time $<0.4 \mathrm{~h}$

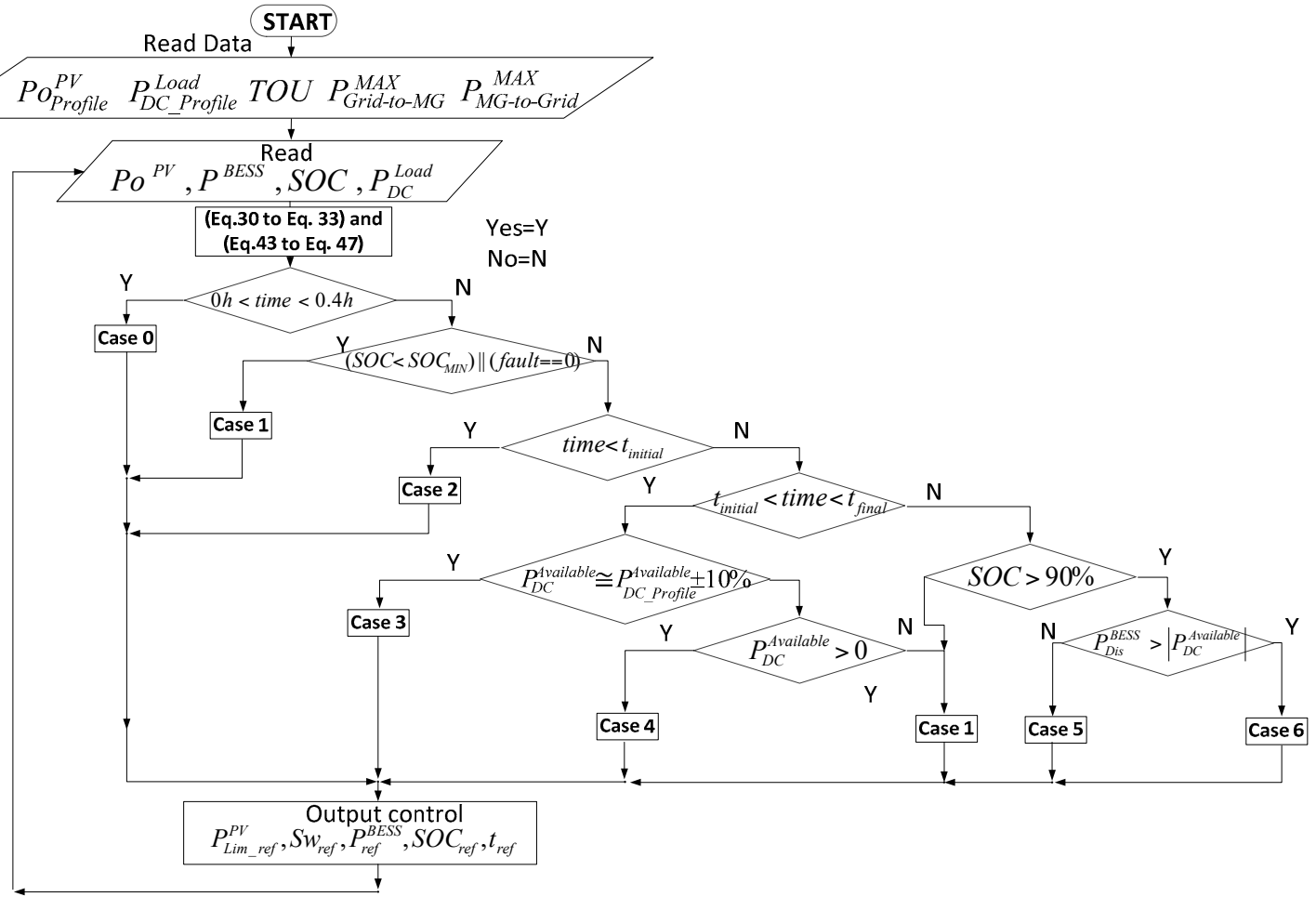

Figure 10. Power management algorithm implemented.

Case 0: At the beginning of each day, case 0 is applied. In the Case 0 , the MGCC requests to the MG operator the daily reference profiles, which are stored in a data table. Based on this information the MGCC plans the power dispatch at the MG. The maximum powers extracted/injected from/to the grid to/from the MG are established by Equations (30) and (31), respectively. The maximum powers 
injected/extracted from/to the DC bus to/from the grid by the ILC are calculated by Equations (32) and (33) respectively.

$$
\begin{gathered}
\left|\hat{P}_{\text {Grid }}\right| \leq P_{\text {Grid-to-MG }}^{M A X} \\
\hat{P}_{\text {Grid }} \leq P_{M G-t o-G r i d}^{M A X} \\
\hat{P}_{D C}^{I L C} \leq \operatorname{MIN}\left(P_{\text {rated }}^{I L C} \frac{P_{M G-t o-G r i d}^{M A X}}{\eta_{I L C}}\right) \\
\left|\hat{P}_{D C}^{I L C}\right| \leq M I N\left(P_{\text {rated }}^{I L C}, \frac{P_{\text {Grid-to-MG }}^{M A X}}{\eta_{I L C}}\right)
\end{gathered}
$$

As it can be seen in Figure 9b, the BESS works in charge mode during off-peak hours (TOU is

\begin{tabular}{|c|c|c|c|c|}
\hline & \multirow[b]{2}{*}{ PV } & \multicolumn{2}{|c|}{ BESS } & \multirow[b]{2}{*}{ DC Load } \\
\hline & & Mode & $\begin{array}{l}\text { Charging } \\
\text { Procedure }\end{array}$ & \\
\hline $\begin{array}{l}0 \\
\ddot{\tilde{z}} \\
\tilde{J}\end{array}$ & \multicolumn{4}{|c|}{$\begin{array}{l}\text { Case } 0 \text { is applied at the beginning of each day. The MGCC performs the daily planning of the power dispatch at the MG. } \\
\text { To perform this, it uses the data of the power profiles and TOU sent from the MG operator. }\end{array}$} \\
\hline \multirow[b]{2}{*}{$\underset{\check{\Xi}}{\tilde{y}}$} & $\mathrm{PV}=\mathrm{Off}$ & Charge mode & $\begin{array}{l}\text { CC-CV based on } \\
\text { Equation (46) }\end{array}$ & $\begin{array}{l}P_{\text {ref }}^{B E S S}=\text { Equation }(46), S O C_{r e f}=100 \% \\
\quad t_{\text {ref }}=t_{\text {initial }}, S w_{\text {ref }}=\{0 \text { or } 1\}\end{array}$ \\
\hline & \multicolumn{4}{|c|}{$\begin{array}{l}\text { Case } 1 \text { indicates that the power management profile predicted for the day has not been correctly fulfilled. This case is } \\
\text { applied when there is not power available at the DC bus, the SOC is less than } 90 \% \text { or when the case } 0 \text { has failed. In this } \\
\text { case, the MGCC complies with the power limit established by the MG operator, without taking into account the electricity } \\
\text { tariff in the power management of the MG. The BESS will operate in charge mode, but won't be able to assure the } \\
\text { DIN41773 charge procedure. }\end{array}$} \\
\hline \multirow{2}{*}{ 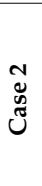 } & $\mathrm{PV}=\mathrm{Off}$ & Charge mode & DIN41773 & $\begin{array}{cc}\text { All Loads } & P_{r e f}^{B E S S}=\text { Equation (38), } S O C_{r e f}=\text { Equation (37) } \\
\text { Connected } & t_{\text {ref }}=t_{\text {initial }}, S w_{r e f}=\{1,1,1,1\}\end{array}$ \\
\hline & \multicolumn{4}{|c|}{$\begin{array}{l}\text { Case } 2 \text { is applied when there is not PV generation, the SOC is less than } 90 \% \text { and the TOU is off-peak. The MGCC } \\
\text { establishes the target SOC (SOC ref }=\text { Equation (37)) at the time interval } t_{\text {initial }} \text { and with a constant power to charge the } \\
\text { batteries. In this case, the BESS can fulfill the DIN41773 charge procedure. }\end{array}$} \\
\hline \multirow[b]{2}{*}{ 急 } & $\begin{array}{l}\text { PV }=\text { On } \\
\text { On MPPT }\end{array}$ & Charge mode & DIN41773 & $\begin{array}{l}P_{r e f}^{B E S S}=\text { Equation (36), } S O C_{r e f}=100 \% \\
t_{\text {ref }}=t_{\text {final }}-t_{\text {initial }}, S w_{\text {ref }}=\{1,1,1,1\}\end{array}$ \\
\hline & \multicolumn{4}{|c|}{$\begin{array}{l}\text { Case } 3 \text { is applied when the PV power is enough to energize all the DC loads, the SOC is less than } 90 \% \text { and the TOU is } \\
\text { off-peak. The MGCC sets the value of } S O C_{r e} f \text { at its maximum possible value }\left(S O C_{r e f}=100 \%\right) \text { at the time interval } t_{f i n a l}- \\
t_{\text {initial }} \text { with a constant power } P_{r e f}^{B E S S}=\text { Equation (36) to charge the batteries. In this case, the BESS can fulfill the DIN } 41773 \\
\text { charge procedure. }\end{array}$} \\
\hline \multirow{2}{*}{ 范 } & $\begin{array}{l}\text { PV }=\text { On } \\
\text { Off MPPT }\end{array}$ & Charge mode & $\begin{array}{l}\text { CC-CV based on } \\
\text { Equation (47) }\end{array}$ & $\begin{array}{c}P_{\text {ref }}^{B E S S}=\text { Equation (47), } S O C_{\text {ref }}=100 \% \\
t_{\text {ref }}=t_{\text {final }}-t_{\text {initial }}, S w_{\text {ref }}=\{1,1,1,1\} \\
P_{\text {Lim_ref }}^{P V}=\text { Equation }(43)\end{array}$ \\
\hline & \multicolumn{4}{|c|}{$\begin{array}{l}\text { In case } 4 \text { a surplus of energy is available from the PV generation and the SOC is less than } 90 \% \text {. The DC loads and the } \\
\text { batteries cannot absorb the excess of power at the DC bus and the Maximum Power Point Tracking is disabled } \\
\text { (Off-MPPT). Power is injected into the grid below the limit imposed by the MG operator. The MGCC sets the target SOC } \\
\text { to } 100 \%\left(S O C_{r e f}=100 \%\right) \text { in the time interval } t_{\text {final }}-t_{\text {initial }} \text { and the batteries are charged at a power } P_{\text {ref }}^{B E S S} \text { according to } \\
\text { Equation (47). }\end{array}$} \\
\hline \multirow{2}{*}{ 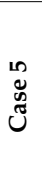 } & $\mathrm{PV}=\mathrm{Off}$ & Discharge & - & $P_{r e f}^{B E S S}=$ Equation (40), Sw $w_{r e f}=\{1,1,1,1\}$ \\
\hline & \multicolumn{4}{|c|}{$\begin{array}{l}\text { Case } 5 \text { is applied when there is not PV generation, TOU is on-peak and SOC is greater than } 90 \% \text {. The BESS must supply } \\
\text { power to the DC bus from the batteries. The discharge power of the batteries Equation (40) is determined to avoid a SOC } \\
\text { lower than } 35 \% \text {. }\end{array}$} \\
\hline \multirow{2}{*}{ 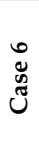 } & $\mathrm{PV}=\mathrm{Off}$ & Discharge & - & $P_{r e f}^{B E S S}=$ Equation (41) $S w_{r e f}=\{1,1,1,1\}$ \\
\hline & \multicolumn{4}{|c|}{$\begin{array}{l}\text { Case } 6 \text { is applied when there is not PV generation and the TOU is on-peak. This case prevents discharge the batteries to } \\
\text { a SOC lower than } \mathrm{SOC}_{\mathrm{MIN}} \text {. The batteries are discharged with a maximum power } P_{r e f}^{B E S} \text { given by Equation (41). }\end{array}$} \\
\hline
\end{tabular}
off-peak), when $\mathrm{kW} \cdot \mathrm{h}$ is cheaper and when the PV power profile is enough to energize all the DC loads $\left(P_{D C \_P r o f i l e}^{\text {Available }}>0\right)$. The available power profile $\left(P_{D C}^{\text {Available }}\right.$ Profile $)$ at the DC bus is given by Equation (34).

Table 6. Summary of the cases applied set by the MGCC. 
When the value of $P_{D C_{-} \text {Profile }}^{\text {Available }}$ starts to be positive, the initial time is detected $\left(t_{\text {initial }}\right)$. The final time $\left(t_{\text {final }}\right)$ is detected once that $P_{D C}^{\text {Available }}$ Prile changes from positive to negative. With the time interval $\left(\mathrm{t}_{\text {initial }}<\right.$ time $\left.<\mathrm{t}_{\text {final }}\right)$ the value of $P_{R E S}^{\text {Available }}$ is calculated. $P_{R E S}^{\text {Available }}$ is the available power from the RES for charging the batteries during the time interval $\left(t_{\text {initial }}<\right.$ time $\left.<t_{\text {final }}\right)$, expressed by the Equation (35). $P_{r e f}^{B E S S}$ is calculated from Equation (36) and the desired SOC $\left(S O C_{r e f}\right)$ which should be reached at $t_{\text {initial }}$ is calculated from Equation (37). When $P_{D C_{-} \text {Profile }}^{\text {Available }}<0$ and the TOU is off-peak, the value of $P_{\text {ref }}^{B E S S}$ is calculated from Equation (38).

$$
\begin{aligned}
& P_{D C_{-} \text {Profile }}^{\text {Available }}=P_{\text {Profile }}^{\text {PV }}-P_{\text {DC__Profile }}^{\text {Load }} \\
& P_{R E S}^{\text {Available }}=\frac{1}{\left(t_{\text {final }}-t_{\text {initial }}\right)} \cdot \int_{t_{\text {initial }}}^{t_{\text {final }}} P_{D C_{-} \text {Profile }}^{\text {Available }} \cdot d t \text { where } P_{D C_{-} \text {Profile }}^{\text {Available }}>0 \\
& P_{\text {ref }}^{\text {BESS }}=\operatorname{MIN}\left(P_{H B-\text { rated }}^{\text {BESS }}, P_{R E S}^{\text {Available }}\right) \\
& S O C_{r e f}=S O C-\frac{P_{R E S}^{\text {Available }} \cdot 100 \% \cdot t_{\text {ref }} \cdot \eta_{\text {Dis }}}{C_{T} \cdot V_{\text {Rated }}^{\text {Bat }}} \text { where } t_{\text {ref }}=\left(t_{\text {final }}-t_{\text {initial }}\right) \\
& P_{\text {ref }}^{B E S S}=\operatorname{MIN}\left(P_{\text {HB-rated }}^{\text {BESS }}\left|\hat{P}_{D C}^{I L C}\right|-P_{D C_{-} \text {Profile }}^{\text {Load }}\right)
\end{aligned}
$$

If $P_{D C_{-} \text {Profile }}^{\text {Available }}<0$ and the TOU is on-peak, the BESS must supply power to the DC bus from the batteries. The discharge power of the batteries for the time interval $\left(t_{r e f}\right)$ is calculated according to Equation (39). $P_{D i s}^{B E S S}$ determines the maximum discharge power to avoid battery discharges leading to values of SOC lower than $35 \%$. If $P_{D i s}^{B E S S}>\left|P_{D C_{-} \text {Profile }}^{\text {Avaliable }}\right|$, the $P_{\text {ref }}^{B E S S}$ is calculated by Equation (40); otherwise, it is calculated by Equation (41).

$$
\begin{gathered}
P_{\text {Dis }}^{B E S S}=\left|\frac{\left(S O C_{M I N}-S O C\right) \cdot Q_{\text {Rated }} \cdot V_{\text {Rated }}^{\text {Bat }}}{100 \% \cdot t_{\text {ref }} \cdot \eta_{\text {Dis }}}\right| \text { where } t_{\text {ref }}=\left(24 h-t_{\text {final }}\right) \\
P_{\text {ref }}^{B E S S}=-M I N\left(P_{H B-\text { rated }}^{\text {BESS }}\left|P_{R E S}^{\text {Available }}\right|\right) \\
P_{\text {ref }}^{B E S S}=-M I N\left(P_{H B-\text { rated }}^{B E S S}, P_{\text {Dis }}^{B E S S}\right)
\end{gathered}
$$

$0.4 \mathrm{~h}<$ time $<\mathrm{t}_{\text {initial }}$

The MGCC begins to execute the strategic planning of case 0 and verifies its compliance. Thus, the MGCC calculates the power flow in the MG every second. The MGCC establishes the PV power limit $\left(P_{\text {Lim_ref }}^{P V}\right)$ by means of Equation (42). Note that in Figure 9a, $P_{\text {Load }}^{D C}$ stands for the power consumed by the DC loads. $S w_{\text {ref }}$ is a vector with binary variables $\{0,1\}$, indicating which DC loads are connected $\{1\}$ or disconnected $\{0\} . P_{\text {Load }}^{D C}$ is calculated by Equation (43). Equation (44) stands for the available power at the DC bus $\left(P_{D C}^{\text {Available }}\right)$ without taking into account the power absorbed from the main grid. $P_{D C-\text { Total }}^{\text {Avaiable }}$ is the total available power at the DC bus and is given by Equation (45).

$$
\begin{gathered}
P_{\text {Lim_ref }}^{P V}=\left|\hat{P}_{D C}^{I L C}\right|+P_{D C}^{L o a d}+P^{B E S S} \\
P_{D C}^{L o a d}=V_{D C} \cdot \sum_{i=1}^{4} I_{D C}^{L o a d}(i) \cdot S w(i)_{r e f} \\
P_{D C}^{\text {Available }}=P o^{P V}-P_{D C}^{L o a d} \\
P_{D C-\text { total }}^{\text {Available }}=\left|\hat{P}_{D C}^{I L C}\right|+P o^{P V}-P_{D C}^{\text {Load }}
\end{gathered}
$$


If $\mathrm{SOC}<\mathrm{SOC}_{\mathrm{MIN}}$, the MGCC activates the fault flag and applies Case 1. Case 1 indicates that the power management profile predicted for the day has not been correctly fulfilled. In this case, if the reference profiles do not fit the power measurements, the MGCC will detect that the power generation predicted for the day is not achieved. In that case, if the SOC of the batteries is lower than $35 \%$, the MGCC will establish that the power limit established by the MG operator is imported from the grid, no matter the value of the electricity tariff. If even in that situation the SOC tends to decrease below 35\%, the MGCC will set the load shedding functionality. The BESS will operate in charge mode, but will not be able to assure the DIN41773 charge procedure. The batteries are charged at a power according to Equation (46).

$$
P_{r e f}^{B E S S}=\operatorname{MIN}\left(P_{H B-\text { rated }}^{\text {BESS }}, P_{D C-\text { total }}^{\text {Available }}\right)
$$

If SOC $>\mathrm{SOC}_{\mathrm{MIN}}$ and the current time of the day is lower than $t_{\text {initial }}$, the MGCC applies case 2. Case 2 is applied at the hours of the day where there is not PV generation and the TOU is off-peak. The MGCC establishes the target SOC $\left(\mathrm{SOC}_{\text {ref }}=\right.$ Equation (37)) at the time interval $\left(t_{\text {ref }}=t_{\text {initial }}\right)$ and with a constant power $\left(P_{r e f}^{B E S S}=\right.$ Equation (38)) to charge the batteries. In this case, the BESS can fulfill the DIN41773 charge procedure.

$$
\mathrm{t}_{\text {initial }}<\text { time }<\mathrm{t}_{\text {final }}
$$

During this time interval the batteries will be charged only with the available power at the PV system $\left(P_{D C}^{\text {Available }}\right)$. If $P_{D C}^{\text {Available }}$ is inside the range $P_{D C}^{\text {Available }}$ Profile $\pm 10 \%$, the MGCC applies case 3 . The MGCC sets the value of $S O C_{r e f}$ at its maximum possible value $\left(S O C_{r e f}=100 \%\right)$ at the time interval $t_{\text {ref }}=t_{\text {final }}-t_{\text {initial }}$ with a constant power $P_{\text {ref }}^{B E S S}=$ Equation (36) to charge the batteries. In this case, the BESS can fulfill the DIN41773 charge procedure.

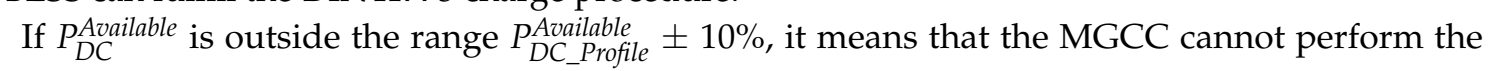
initial planning. If $P_{D C}^{\text {Available }}>0$, then case 4 is applied. On the contrary $\left(P_{D C}^{\text {Available }}<0\right)$, case 1 is applied.

In case 4, a surplus of energy is available from the PV generation. Power is injected to the grid below the limit imposed by the MG operator. The Maximum Power Point Tracking is off (Off-MPPT). The MGCC sets the target SOC to $100 \%\left(S O C_{\text {ref }}=100 \%\right)$ in the time interval $t_{\text {ref }}=t_{\text {final }}-t_{\text {initial }}$ and the batteries are charged at a power $P_{r e f}^{B E S S}$ according to Equation (47).

$$
t_{\text {final }}<\text { time }<24 \mathrm{~h}
$$

During this time interval the BESS should supply the necessary power to the DC bus, because the TOU is on-peak and the PV power is not enough to feed all the DC loads. If SOC $<90 \%$, the MGCC activates the fault flag and applies case 1.

Otherwise, if SOC $>90 \%$, it means that MGCC can perform the initial planning.

If $P_{D i s}^{B E S S}<\left|P_{D C}^{\text {Available }}\right|$, then case 5 is applied. In case 5 the batteries are discharged with a power $P_{\text {ref }}^{B E S S}$ given by Equation (40). In the opposite case, if $P_{D i s}^{B E S S}>\left|P_{D C}^{\text {Available }}\right|$, case 6 is applied, because the necessary power at the $\mathrm{DC}$ bus is higher than the maximum available discharge power at the batteries. Case 6 avoids discharging the batteries to a SOC lower than SOC $_{\text {MIN }}$. The batteries are discharged with a maximum power $P_{r e f}^{B E S S}$ given by Equation (41).

$$
P_{\text {ref }}^{\text {BESS }}=\operatorname{MIN}\left(P_{H B-\text { rated }}^{\text {BESS }}, P_{D C}^{\text {Available }}\right)
$$

\section{Experimental and Simulation Results}

Figure 11a and b show a block diagram and a picture of the power converters operating in the experimental DC microgrid, respectively. The power converters specifications are shown in Table 7. First, several microgrid scenarios have been studied by means of the of the PSIM ${ }^{\mathrm{TM}}$ simulator [63]. After that, the proposed power management algorithm and the BESS have been tested in an experimental MG and compared with the simulated results. The proposed battery charging procedure shown in Section 3 has been verified by simulation \#1 and by experiment \#1. This procedure 
has been executed four times, each time with a different charging current: $I_{(\mathrm{Ch})}^{\mathrm{Bat}}=15 \mathrm{~A}, 12 \mathrm{~A}, 10 \mathrm{~A}$ and $5 \mathrm{~A}$. The power management of the MG described in Section 4 has been validated by simulation \#2 and by experiment \#2. In experiment \#3 the response of the MG to an abrupt change of the power flow between the MG and the main grid is studied. Finally, the communication delays between a measurement request from the MGCC and the response of the BESS are shown in experiment \#4.

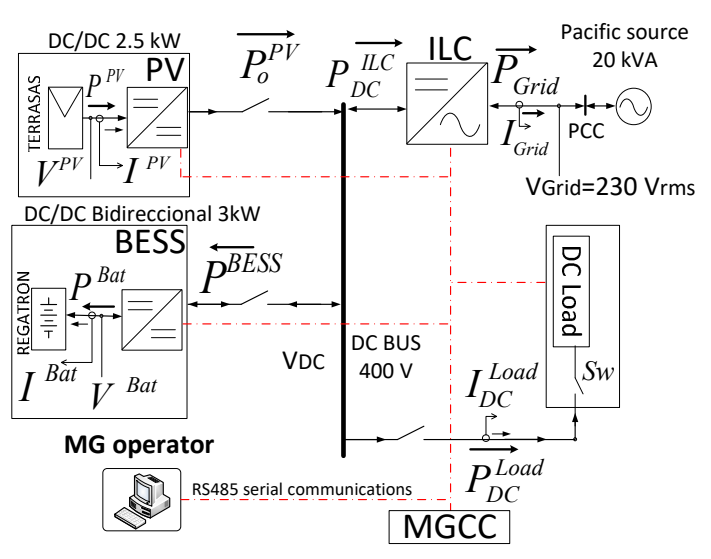

(a)

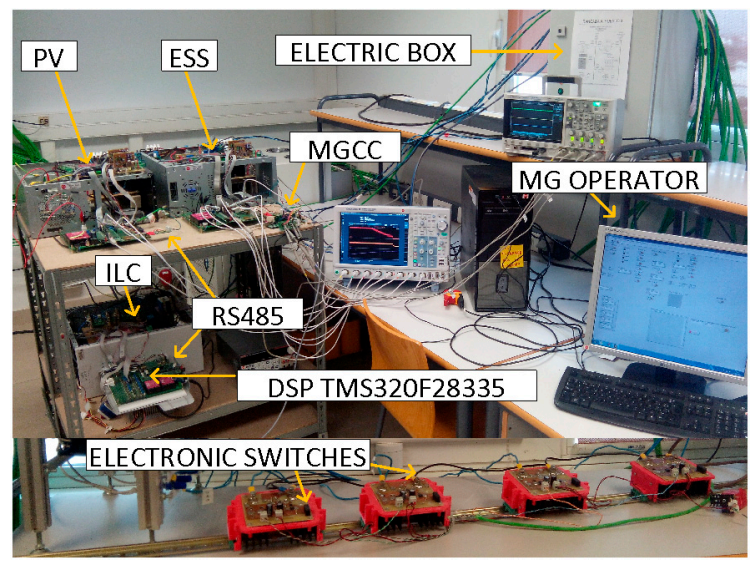

(b)

Figure 11. Experimental DC microgrid: (a) Block diagram of the experimental DC microgrid (b) Picture of the power converters operating in the experimental DC microgrid.

\subsection{Simulation \#1}

The DIN41773 compatible charging procedure has been verified by simulation \#1, whose results are shown in Figure 12. It is worth pointing out that, in order to check the charging procedure with several values of the charge current in a short simulation time, the value of $Q_{\text {Rated }}$ was downscaled in simulations \#1 and \#2 to 2 A.h.

Table 7. Specifications of the power converters operating in the DC microgrid.

\begin{tabular}{ccc}
\hline ILC & BESS & PV \\
\hline$P_{\text {Rated }}^{I L C}=10 \mathrm{~kW}$ & $P_{H B \text { Rated }}^{\text {BESS }}=3 \mathrm{~kW}$ & $P_{\text {Rated }}^{P V}=2.5 \mathrm{~kW}$ \\
$V_{\text {Grid }}=230 \mathrm{~V}$ and $F_{\text {Grid }}=50 \mathrm{~Hz}$ & $V^{\text {Bat }}=216 \mathrm{~V}$ & $\mathrm{~V}^{\mathrm{PV}}=306 \mathrm{~V}$ \\
$V_{D C}=400 \mathrm{~V}$ & $F_{\text {sw_BESS }}=16 \mathrm{kHz}$ & $\mathrm{F}_{\text {SW_PV }}=16 \mathrm{kHz}$ \\
$F_{\text {sw_ILC }}=12.8 \mathrm{kHz}$ & $T^{\text {Bat }}=25^{\circ}{ }^{\circ} Q_{\text {Rated }}=2 \mathrm{~A} \cdot \mathrm{h}$ & PV Panel: Atersa A-250P GSE \\
\hline
\end{tabular}

The batteries are initially charged at CC with several values of $I_{(\mathrm{Ch})}^{\mathrm{Bat}}(15 \mathrm{~A}, 12 \mathrm{~A}, 10 \mathrm{~A}$ and $5 \mathrm{~A})$ until a maximum charging voltage $\left(V_{(\mathrm{Ch})}^{\mathrm{Bat}}\right)$ is reached. When $V_{(\mathrm{Ch})}^{\mathrm{Bat}}$ is reached, the batteries are charged at $\mathrm{CV}$ at that value of $V_{(\mathrm{Ch})}^{\mathrm{Bat}}$. The value of $V_{(\mathrm{Ch})}^{\mathrm{Bat}}$ depends on the temperature and on the charging current value. $V_{(\mathrm{Ch})}^{\text {Bat }}$ is given by Equation (27). A value of $T^{\text {Bat }}=25^{\circ} \mathrm{C}$ has been considered.

Finally, once the current absorbed by the batteries is lower than a pre-set tail current value $\left(I_{\text {tail }}^{\text {Bat }}=1 \mathrm{~A}\right)$, then the battery voltage is set at a constant floating voltage value $\left(V_{\text {Float }}^{\text {Bat }}\right)$ that is given by Equation (28). 


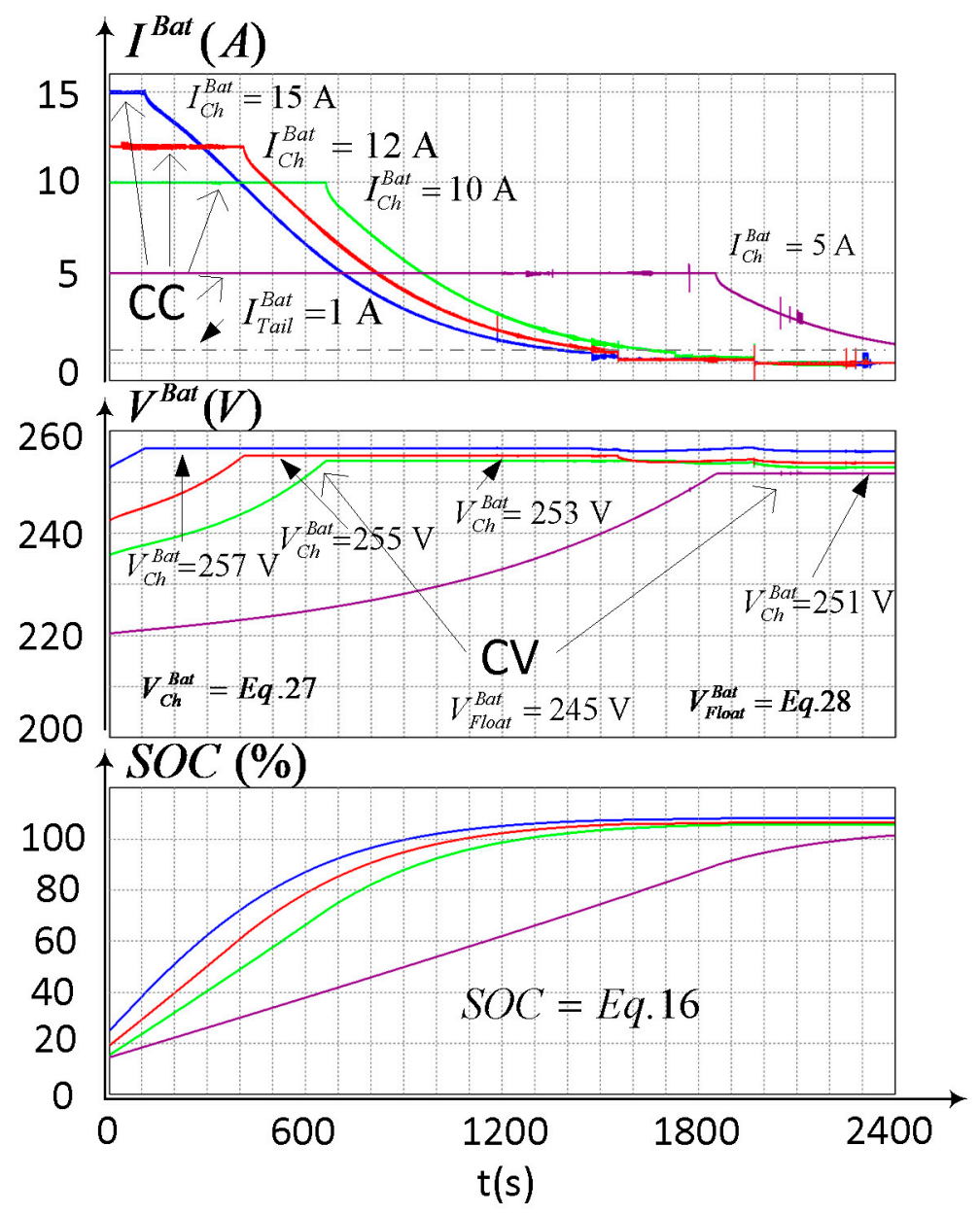

Figure 12. Simulation \#1. Simulation waveforms of the charging procedure: $I^{B a t}, V^{B a t}$ the SOC.

\subsection{Simulation \#2}

In order to check the proposed power management algorithm described in Section 4, different scenarios with a short simulation time have been analyzed. In order to avoid too long simulation times, the reference profiles were adjusted in this study to a whole equivalent 'daily' period of $2400 \mathrm{~s}$, where $100 \mathrm{~s}$ corresponds to one hour of the day. The value of $Q_{\text {Rated }}$ was downscaled for performing the tests \#1 and \#2 to $2 \mathrm{~A} \cdot \mathrm{h}$. The reference profiles that were used to plan the power dispatch in the MG are shown in Table 8. Figure 13 shows the simulation waveforms of the power flow at the DC bus of the MG in one equivalent day. The scenarios under study are: (i) Different values of the TOU tariffs, (ii) variations of the available PV power and (iii) variations of the power consumed by the loads connected to the DC bus. Those variations can be observed in Figure 13, being labeled as TOU, $P_{o}{ }^{P V}$ and $P_{\text {Load }}^{D C}$, respectively. The evolution of the power flow $\left(P_{D C}^{\text {Available }}, P_{D C}^{I L C}, P^{B E S S}\right)$, the SOC and the batteries current $\left(I^{B a t}\right)$, can be observed in the lower part of Figure 13.

The analysis has been performed according to the following time intervals:

Interval $1(0<$ time $<40 \mathrm{~s})$

At $t=0 \mathrm{~s}$, it is assumed that the batteries have been discharged the previous day to $\mathrm{SOC}=38 \%$. During the duration of the time interval corresponding to case 0 , the power dispatch in the MG is done. Depending on the reference profiles of Table 8, the MGCC detects the time intervals where the batteries will be charged only with the available PV power and when the TOU is off-peak. The time values are: $t_{\text {initial }}=900 \mathrm{~s}, t_{\text {final }}=1520 \mathrm{~s}$. 
Interval $2(40 \mathrm{~s}<$ time $<900 \mathrm{~s})$

This time interval represents the hours of the night and the early hours of the day when the PV power is not enough to energize all the loads and the TOU is off-peak. The MGCC applies case 2. The MGCC sends to the BESS the target SOC, SOC ref $=68 \%$ at $t_{\text {ref }}=900 \mathrm{~s}$ and the reference of the available power at the DC bus to charge the batteries, $P_{r e f}^{B E S S}=$ Equation (38). However, the BESS only uses the power needed, $P^{B E S S}=0.9 \mathrm{~kW}$, to reach the target $S O C$, which is lower than the power available at the DC bus, $P_{r e f}^{B E S S} \cong 3 \mathrm{~kW}$. In this case, the MGCC orders the transfer of the power needed at the DC bus from the grid through the ILC, with a value below the limit imposed by Equation (33). At $t=700 \mathrm{~s}$ the value of the power imported from the grid by the ILC is: $P_{D C}^{I L C}=-3 \mathrm{~kW}$. Note that at this time interval $P^{B E S S}$ takes a constant value $(0.9 \mathrm{~kW})$. The BESS complies with the DIN41773 charging procedure.

Table 8. Reference profiles sent to the MGCC for the power dispatch planning in the MG.

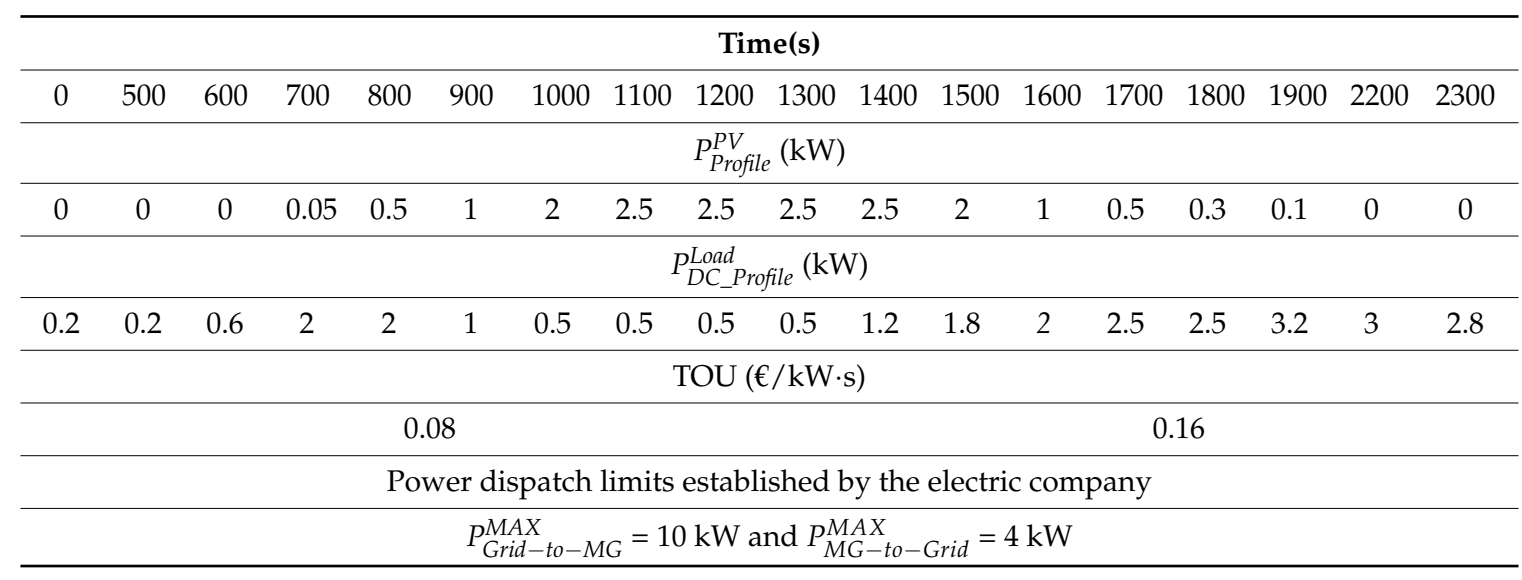

Interval $3(900 \mathrm{~s}<$ time $<1520 \mathrm{~s})$

This time interval represents the hours of the day when the PV power is enough to energize all the loads. The MGCC applies case 3. The MGCC sends to the BESS the target SOC, $S O C_{r e f}=100 \%$, at $t_{\text {ref }}=620 \mathrm{~s}$, and the reference of the available power at the DC bus to charge the batteries calculated initially during case $0, P^{B E S S} \cong 1.56 \mathrm{~kW}$ (Equation (36)). In this case, the MGCC can export the excess power from the DC bus to the grid through the ILC. Note that the batteries have reached a value SOC $=97.2 \%$ at $t=1520 \mathrm{~s}$.

Interval $4(1520 \mathrm{~s}<$ time $<2400 \mathrm{~s})$

This time interval represents the hours of the day when the TOU is on-peak and the PV power is not enough to energize all the loads. Taking into account that the BESS is charged (SOC $\geq 80 \%$ ), the MGCC transfers the needed power from the battery bank to the DC bus through the BESS. This interval is divided into three subintervals. 


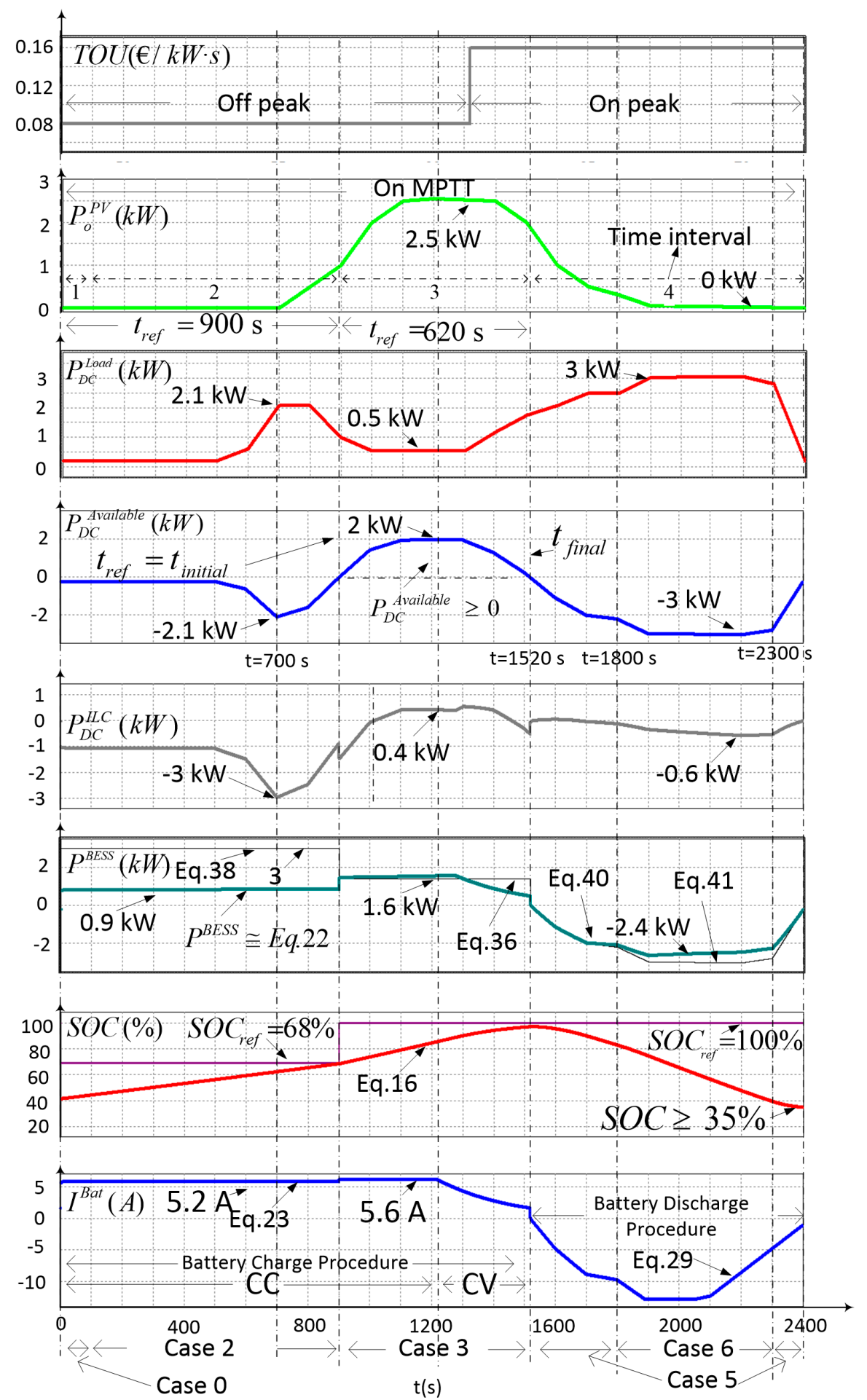

Figure 13. Simulation \#2: Simulation results of the power management in the MG. $100 \mathrm{~s}$ corresponds to $1 \mathrm{~h}$.

$1520 \mathrm{~s}<$ time < $1800 \mathrm{~s}$ : The MGCC applies case 5 . In this case, the MGCC sends to the BESS the power reference, $P_{r e f}^{B E S S}=$ Equation (40) and the target $S O C, S O C_{r e f}=35 \%$, at $t_{r e f}=880 \mathrm{~s}$. The MGCC orders to import the minimum possible power from the grid.

$2000 \mathrm{~s}<$ time $<2300 \mathrm{~s}$ : The MGCC applies case 6 . In this case, the needed power at the DC bus is higher than the maximum available discharge power at the batteries. The MGCC sends to the BESS 
the power reference, $P_{\text {ref }}^{B E S S}=$ Equation (41). The MGCC orders to import the minimum possible power from the grid.

$2300 \mathrm{~s}<$ time < $2400 \mathrm{~s}$ : The MGCC applies case 5. In this case, the MGCC sends to the BESS the power reference, $P_{r e f}^{B E S S}=$ Equation (40). The MGCC orders to import the minimum possible power from the grid.

\subsection{Experiment \#1}

A $3 \mathrm{~kW}$ bidirectional BESS a $2.5 \mathrm{~kW}$ PV system and a single-phase $10 \mathrm{~kW}$ ILC, have been built and connected to the experimental DC microgrid. Each power converter has its own TMS320F28335 DSP controller to perform its primary control and its serial RS485 communication system. The power converters specifications are the same as those shown in Table 7. All the experimental waveforms have been obtained by means of a Yokogawa DLM4038, 8-channel oscilloscope (Yokogawa Iberia S.A., Madrid, Spain). The batteries have been emulated by a $20 \mathrm{~kW}$ bidirectional DC source/battery emulator model TC.GSS-Bidirectional-DC-PSU from Regatron AG (Rorschach, Switzerland). The PV array has been emulated by means of a $10 \mathrm{~kW}$ PV array simulator TerraSAS ETS1000/10 from Ametek (San Diego, CA, USA). LabVIEW software (National Instruments Spain, Madrid, Spain) has been used for emulating the MG operator.

The DIN41773 compatible battery charging procedure has been verified in experiment \#1. The procedure was tested with four different values of the charging current: $I_{(\mathrm{Ch})}^{\mathrm{Bat}}=15 \mathrm{~A}, 12 \mathrm{~A}$, $10 \mathrm{~A}$ and $5 \mathrm{~A}$, corresponding to Figure $14 \mathrm{a}-\mathrm{d}$, respectively. As it can be observed from Figure 14, the reference value $\left(V_{(C h)}^{B a t}\right)$ of the voltage control loop is properly adjusted depending on the values of $I_{(\mathrm{Ch})}^{\mathrm{Bat}}$ and of the temperature. $V_{(\mathrm{Ch})}^{\mathrm{Bat}}$ is given by Equation (27). A value of $T^{\text {Bat }}$ around $25^{\circ} \mathrm{C}$ has been obtained during this experiment.

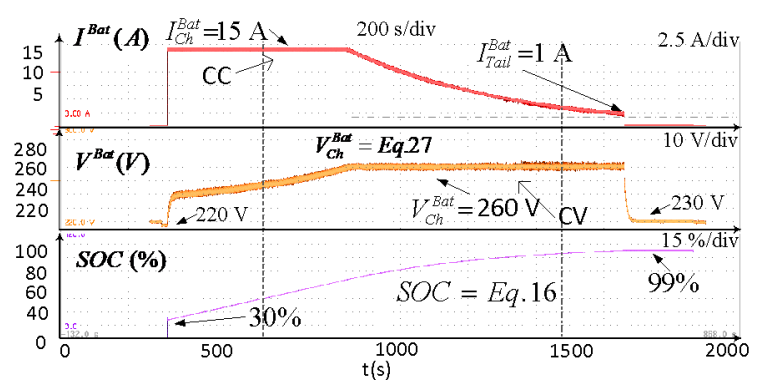

(a)

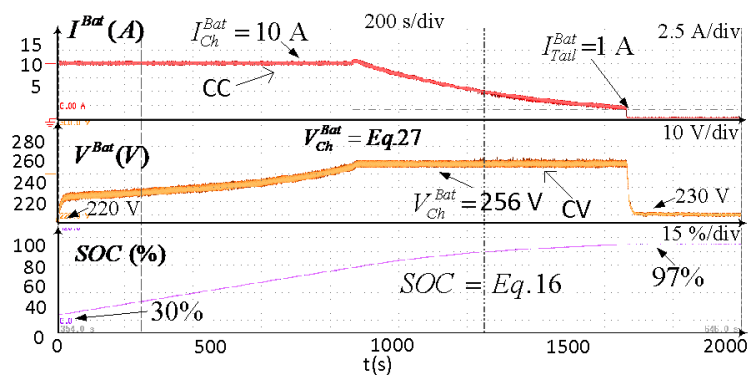

(c)

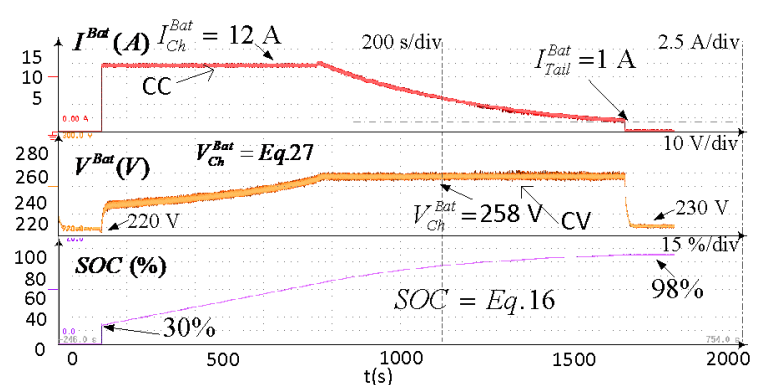

(b)

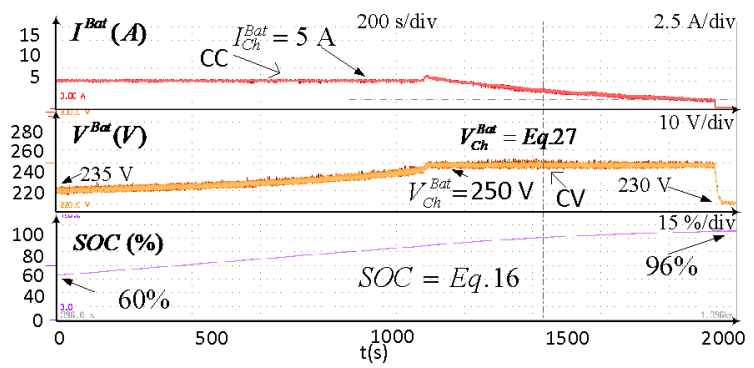

(d)

Figure 14. Experiment \#1. Waveforms of the implemented charging procedure for different values of the charging current: (a) $I_{(\mathrm{Ch})}^{B a t}=15 \mathrm{~A} ;(\mathbf{b}) I_{(\mathrm{Ch})}^{B a t}=12 \mathrm{~A} ;(\mathbf{c}) I_{(\mathrm{Ch})}^{B a t}=10 \mathrm{~A}$ and $(\mathbf{d}) I_{(\mathrm{Ch})}^{B a t}=5 \mathrm{~A}$.

\subsection{Experiment \#2}

The evolution of the powers $\left(P_{o}{ }^{P V}, P^{B E S S}, P_{\text {Load }}^{D C}, P_{D C}^{I L C}\right)$, currents $\left(I^{B a t}, I^{P V}\right)$, SOC and voltages $\left(V^{B a t}\right.$, $V^{P V}$ ) of the DC micrigrid can be observed in Figure 15. Initially, the MGCC applies case 0 and calculates 
the time intervals where the batteries will be only charged with the power available at the PV system, being the TOU is off-peak, yielding the values: $t_{\text {initial }}=420 \mathrm{~s}, t_{\text {final }}=1300 \mathrm{~s}$. The analysis is performed according to the following time intervals:

Interval $1(0<$ time $<420 \mathrm{~s})$

During this time interval the PV power $\left(P_{o}{ }^{P V}\right)$ is not enough to energize all the loads $\left(P_{\text {Load }}^{D C}\right)$ and the TOU is off-peak. The MGCC applies case 2. The MGCC sends to the BESS the target SOC value, $S O C_{r e f}=50 \%$, during the time interval $t_{r e f}=420 \mathrm{~s}$. It also sends the reference of the available power at the DC bus to charge the batteries, $P_{r e f}^{B E S S}=3 \mathrm{~kW}$. However, the BESS only uses the power needed $\left(P^{B E S S}=\right.$ Equation $\left.(12)=0.4 \mathrm{~kW}\right)$ to reach the target SOC, $S O C_{r e f}=50 \%$. In this case, the MGCC orders to import the power needed at the DC bus from the grid through the ILC. At $t=100 \mathrm{~s}$, the values are: $P_{O}{ }^{P V}>0, \mathrm{SOC}=40 \%$ and $P_{D C}^{I L C}=-1.2 \mathrm{~kW}$.

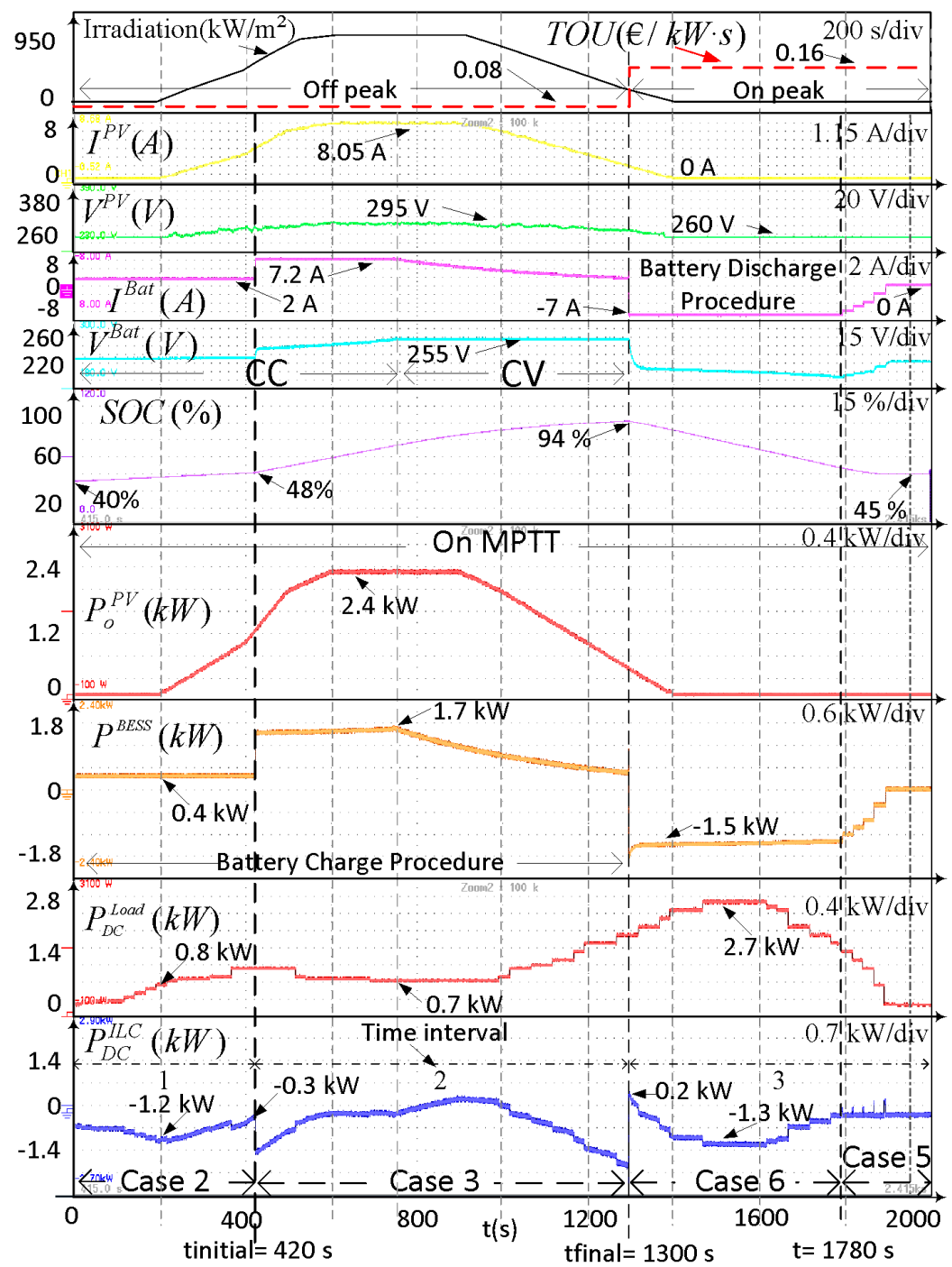

Figure 15. Experiment \#2. Experimental results of the power management in the MG.

Interval $2(420 \mathrm{~s}<$ time $<1300 \mathrm{~s})$

During this time interval, the PV power is enough to energize all the loads. At $t=420 \mathrm{~s}$ the MGCC applies case 3 . The MGCC sends to the BESS the new power reference, $P_{\text {ref }}^{B E S S}=$ Equation $(36)=1.7 \mathrm{~kW}$ and the target SOC, $S O C_{r e f} \cong 100 \%$, during a time interval $t_{r e f}=880 \mathrm{~s}$. In this case, the MGCC only charges 
the batteries with the available power at the PV system and imports the minimum power from the grid through the ILC. At $t=420 \mathrm{~s}$ the power managed by the ILC is: $P$ ILC $\cong-0.3 \mathrm{~kW}$. The DIN41773 charging procedure is verified in this time interval. At $t=800 \mathrm{~s}$, the BESS changes from CC mode to CV mode with $V_{(\mathrm{Ch})}^{\mathrm{Bat}}=255 \mathrm{~V}$. Note that the batteries have reached SOC $=94 \%$ at $t=1300 \mathrm{~s}$.

Interval $3(1300 \mathrm{~s}<$ time $<2000 \mathrm{~s})$

At $t=1300 \mathrm{~s}$ the TOU changes from off-peak $(0.08 € / \mathrm{kW} \cdot \mathrm{s})$ to on-peak $(0.16 € / \mathrm{kW} \cdot \mathrm{s})$. This time interval represents the hours of the day when the TOU is on-peak and the PV power is not enough to energize all the loads. Taking into account that the BESS is charged, SOC $\geq 80 \%$ (at $t=1300 \mathrm{~s}$, SOC $=94 \%$ ), the MGCC transfers the necessary power from the battery bank to the DC bus through the BESS. This interval is divided into two subintervals.

$1300 \mathrm{~s}<$ time < $1780 \mathrm{~s}$ : The MGCC applies case 6 . In this case, the MGCC calculates the maximum discharge power of the batteries $\left(P_{D i s}^{B E S S}\right)$ to discharge the batteries to a level which is higher than $\mathrm{SOC}_{\mathrm{MIN}}$, being $S O C_{r e f}>35 \%$ at $t_{r e f}=700 \mathrm{~s}$. The MGCC sends the power reference to the BESS, $P_{r e f}^{B E S S}=$ Equation (41), and orders to import the needed power from the grid.

$1780 \mathrm{~s}<$ time < $2000 \mathrm{~s}$ : The MGCC applies case 5 . In this case, the MGCC sends to the BESS the new power reference, $P_{r e f}^{B E S S}=$ Equation (40), ordering to import the minimum possible power from the grid.

\subsection{Experiment \#3}

The ILC regulates the voltage of the DC bus in grid connected mode, and performs the synchronization with the main grid. To verify the stability of the DC bus during heavy transients, an abrupt change from $-0.8 \mathrm{~kW}$ to $1.9 \mathrm{~kW}(2.7 \mathrm{~kW}$ step at $t=9.3 \mathrm{~s})$ of the power flow from the DC bus to the main grid is forced. The experimental waveforms when the MG changes from exporting to importing power to/from the main grid are shown in Figure 16.

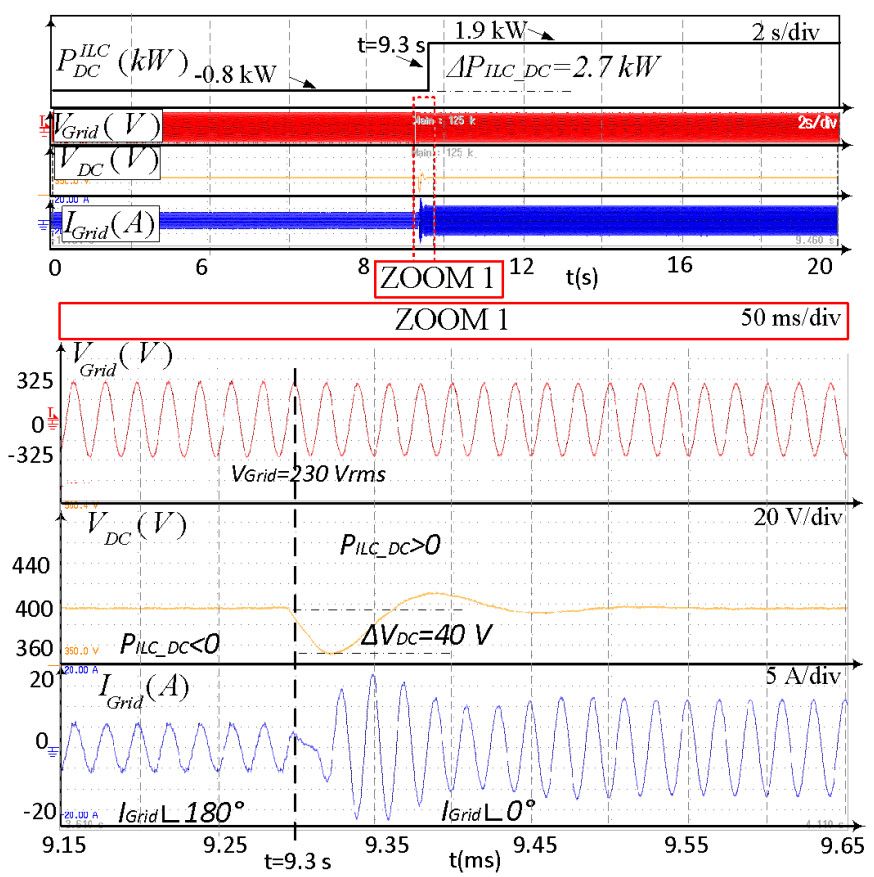

Figure 16. Experiment \#3. Experimental results of the abrupt change in power flow from the DC bus to the main grid.

As it can be seen in ZOOM 1 of Figure 16, the DC bus voltage is stable and a small transient deviation occurs of $\Delta V_{D C}=38 \mathrm{~V}$, i.e., less of $10 \%$ of the DC bus voltage. A low distortion of $I_{\text {Grid }}$ can be observed in the transition from exporting to importing power to/from the $\mathrm{AC}$ grid. 


\subsection{Experiment \#4}

In this work, RS485 serial communications are used with the MODBUS protocol. This protocol allows for the exchange of information between the MGCC and the different devices connected to the MG with an adequate performance in MG. The implemented RS485 communications allow for the calculation of the power values in several points of the MG quickly and accurately. The communications delay of the receiving $(R X)$ and transmitting (TX) signals between the MGCC and the BESS can be observed in Figure 17. The RS485 communication bus baud rate is 9600 bps. The time difference between a MGCC request and the $\mathrm{BESS}$ response is $18 \mathrm{~ms}$. The proposed power management algorithm is running every second in the MG under study, so that the communication delays are not critical.

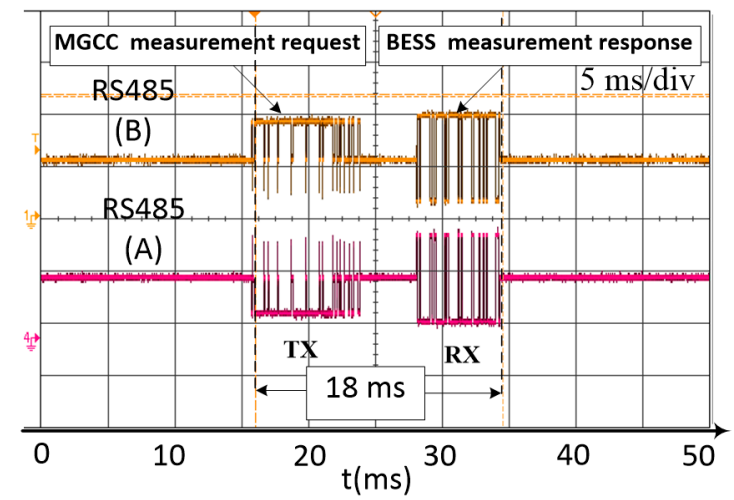

Figure 17. Experiment \#4. Communication delays between the MGCC and the BESS.

\section{Conclusions}

In this paper it has been shown the design and operation of a BESS for a grid-connected DC Microgrid with PV generation. The bidirectional power converter conforming the BESS has been modeled and verified according to any change of the battery charge/discharge currents, the SOC, the battery voltage and variations of the DC bus voltage. The BESS has a BMS that maximizes the battery life time, being compatible with a DIN41773 battery charging procedure and complying with the manufacturer specifications at the same time. The proposed procedure changes the charging parameters of the batteries depending on the MG states.

A MGCC has been used for the power management of the DC microgrid. The MGCC estimates the available power at the DC bus to charge the batteries and a target SOC in the batteries at different hours of the day. The MGCC daily plans the power dispatch in the MG and complies with two objectives: (i) to import the minimum possible power from the grid, and (ii) to charge the batteries during off-peak times and with the surplus of energy is available from the PV resources. These strategies allow for reducing the electricity bill.

The experimental and simulation results show that the implemented method allows for properly planning the power dispatch at the DC microgrid, fulfilling the battery charging procedure recommended by the manufacturer at the same time, expanding battery life.

Author Contributions: R.S.-P., E.F. and G.G. proposed the main idea, conceived and designed the experiments; R.S.-P. performed the experiments; S.M. designed the communication; S.M. and R.G.-M. reviewed the article; R.S.-P., E.F. and G.G. wrote this paper.

Funding: This research was funded by the Spanish Ministry of Economy and Competitiveness (MINECO) and by the European Regional Development Fund (ERDF) under Grant ENE2015-64087-C2-2.

Acknowledgments: This work has been cofinanced by the Spanish Ministry of Economy and Competitiveness (MINECO) and by the European Regional Development Fund (ERDF) under Grant ENE2015-64087-C2-2.

Conflicts of Interest: The authors declare no conflict of interest. 


\section{Abbreviations}

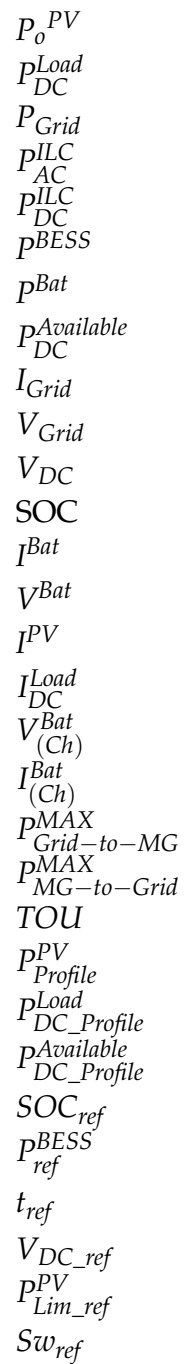

Power supplied by the PV arrays seen from the DC bus

Overall power consumed by the DC loads

Power injected from the DC microgrid to the grid

Power injected from the DC bus to the grid by the ILC, measured at the AC side of the ILC

Power injected from the DC bus to the grid by the ILC, measured at the DC side of the ILC

Battery charge power seen from the DC bus

Battery charge power

Power available at the DC bus

RMS Current injected from the DC microgrid to the grid

RMS value of the grid voltage

DC bus voltage

State of charge of the battery bank

Battery bank charge current

Battery bank voltage

Current supplied by the PV array

Overall current consumed by the DC loads

Reference of the charging voltage

Reference of the charging current

Maximum power that can be extracted from the main grid to the MG

Maximum power that can be injected from the MG to the main grid

Time of use of electricity

Reference profiles of PV generation

Reference profiles of power consumed by the loads

The available power profile at the DC bus

Desired SOC in the batteries

Reference power for charging/discharging the batteries from/to DC bus

Time interval in which BESS must reach the target SOC with $P_{r e f}^{B E S S}$

Reference of the DC bus voltage

Maximum power that should be extracted from the PV sources

Reference of the DC load switches (load 1 to 4 )

\section{References}

1. Dragičević, T.; Lu, X.; Vasquez, J.C.; Guerrero, J.M. DC Microgrids-Part I: A Review of Control Strategies and Stabilization Techniques. IEEE Trans. Power Electron. 2016, 31, 4876-4891.

2. Baek, J.; Choi, W.; Chae, S. Distributed Control Strategy for Autonomous Operation of Hybrid AC/DC Microgrid. Energies 2017, 10, 373. [CrossRef]

3. Rahimi-Eichi, H.; Ojha, U.; Baronti, F.; Chow, M.Y. Battery Management System: An Overview of Its Application in the Smart Grid and Electric Vehicles. IEEE Ind. Electron. Mag. 2013, 7, 4-16. [CrossRef]

4. Sujitha, N.; Krithiga, S. RES based EV battery charging system: A review. Renew. Sustain. Energy Rev. 2017, 75, 978-988. [CrossRef]

5. Renewables 2017 Global Status Report. Available online: http://www.ren21.net/wp-content/uploads / 2017/06/17-8399_GSR_2017_Full_Report_0621_Opt.pdf (accessed on 5 July 2018).

6. Chen, H.; Cong, T.N.; Yang, W.; Tan, C.; Li, Y.; Ding, Y. Progress in electrical energy storage system: A critical review. Prog. Nat. Sci. 2009, 19, 291-312. [CrossRef]

7. May, G.J.; Davidson, A.; Monahov, B. Lead batteries for utility energy storage: A review. J. Energy Storage 2018, 15, 145-157. [CrossRef]

8. Joseph, A.; Shahidehpour, M. Battery storage systems in electric power systems. In Proceedings of the 2006 IEEE Power Engineering Society General Meeting, Montreal, QC, Canada, 18-22 June 2006; p. 8.

9. IRENA. Available online: http:/ / www.irena.org/eventdocs / Battery\%20storage \%20June \%201\%202017\% 20MICHAEL\%20TAYLOR\%20PDF\%20version.pdf (accessed on 3 February 2018). 
10. Hussein, A.A.; Fardoun, A.A. Design considerations and performance evaluation of outdoor PV battery chargers. Renew. Energy 2015, 82, 85-91. [CrossRef]

11. Xing, Y.; Ma, E.W.M.; Tsui, K.L.; Pecht, M. Battery Management Systems in Electric and Hybrid Vehicles. Energies 2011, 4, 1840-1857. [CrossRef]

12. Wu, D.; Tang, F.; Dragicevic, T.; Guerrero, J.M.; Vasquez, J.C. Coordinated Control Based on Bus-Signaling and Virtual Inertia for Islanded DC Microgrids. IEEE Trans. Smart Grid 2015, 6, 2627-2638. [CrossRef]

13. Dou, C.; Zhang, Z.; Yue, D.; Zheng, Y. MAS-Based Hierarchical Distributed Coordinate Control Strategy of Virtual Power Source Voltage in Low-Voltage Microgrid. IEEE Access 2017, 5, 11381-11390. [CrossRef]

14. Bracale, A.; Caramia, P.; Carpinelli, G.; Mancini, E.; Mottola, F. Optimal control strategy of a DC micro grid. Int. J. Electr. Power Energy Syst. 2015, 67, 25-38. [CrossRef]

15. Yue, J.; Hu, Z.; Li, C.; Vasquez, J.C.; Guerrero, J.M. Economic Power Schedule and Transactive Energy through an Intelligent Centralized Energy Management System for a DC Residential Distribution System. Energies 2017, 10, 916. [CrossRef]

16. Gao, L.; Liu, Y.; Ren, H.; Guerrero, J.M. A DC Microgrid Coordinated Control Strategy Based on Integrator Current-Sharing. Energies 2017, 10, 1116. [CrossRef]

17. Unamuno, E.; Barrena, J.A. Hybrid AC/DC microgrids-Part II: Review and classification of control strategies. Renew. Sustain. Energy Rev. 2015, 52, 1123-1134. [CrossRef]

18. Zia, M.F.; Elbouchikhi, E.; Benbouzid, M. Microgrids energy management systems: A critical review on methods, solutions, and prospects. Appl. Energy 2018, 222, 1033-1055. [CrossRef]

19. Feng, X.; Shekhar, A.; Yang, F.E.; Hebner, R.; Bauer, P. Comparison of Hierarchical Control and Distributed Control for Microgrid. Electr. Power Compon. Syst. 2017, 45, 1043-1056. [CrossRef]

20. De Brabandere, K.; Bolsens, B.; van den Keybus, J.; Woyte, A.; Driesen, J.; Belmans, R. A Voltage and Frequency Droop Control Method for Parallel Inverters. IEEE Trans. Power Electron. 2007, 22, 1107-1115. [CrossRef]

21. Kaur, A.; Kaushal, J.; Basak, P. A review on microgrid central controller. Renew. Sustain. Energy Rev. 2016, 55, 338-345. [CrossRef]

22. Marzal, S.; González-Medina, R.; Salas-Puente, R.; Figueres, E.; Garcerá, G. A Novel Locality Algorithm and Peer-to-Peer Communication Infrastructure for Optimizing Network Performance in Smart Microgrids. Energies 2017, 10, 1275. [CrossRef]

23. Gamarra, C.; Guerrero, J.M. Computational optimization techniques applied to microgrids planning: A review. Renew. Sustain. Energy Rev. 2015, 48, 413-424. [CrossRef]

24. Li, W.; Logenthiran, T.; Woo, W.L.; Phan, V.T.; Srinivasan, D. Implementation of demand side management of a smart home using multi-agent system. In Proceedings of the 2016 IEEE Congress on Evolutionary Computation (CEC), Vancouver, BC, Canada, 24-29 July 2016; pp. 2028-2035.

25. Joo, I.Y.; Choi, D.H. Optimal household appliance scheduling considering consumer's electricity bill target. IEEE Trans. Consum. Electron. 2017, 63, 19-27. [CrossRef]

26. Roozbehani, M.; Dahleh, M.A.; Mitter, S.K. Volatility of power grids under real-time pricing. IEEE Trans. Power Syst. 2012, 27, 1926-1940. [CrossRef]

27. Carpinelli, G.; Khormali, S.; Mottola, F.; Proto, D. Optimal operation of electrical energy storage systems for industrial applications. In Proceedings of the 2013 IEEE Power \& Energy Society General Meeting, Vancouver, BC, Canada, 21-25 July 2013; pp. 1-5.

28. Erol-Kantarci, M.; Hussein, T.M. Prediction-based charging of PHEVs from the smart grid with dynamic pricing. In Proceedings of the IEEE Local Computer Network Conference, Denver, CO, USA, 10-14 October 2010; pp. 1032-1039.

29. Hooppecke. Operating Instructions Valve Regulated Stationary Lead-Acid Batteries. Available online: http:/ / www.hoppecke-us.com/tl_files/hoppecke/Documents/HO-US/Operating_Instructions_sealed_ stationary_lead_acid_batteries_en1111.pdfaccessed on 13 October 2017).

30. TAB Batteries. Available online: http://www.tabspain.com/wp-content/uploads/informacion-tecnica/ renovables / curvas-y-tablas / din-41773-y-din-41774-para-baterias-pzs.pdf (accessed on 13 October 2017).

31. Lu, L.; Han, X.; Li, J.; Hua, J.; Ouyang, M. A review on the key issues for lithium-ion battery management in electric vehicles. J. Power Sources 2013, 226, 272-288. [CrossRef]

32. Hussein, A.A.; Batarseh, I. A Review of Charging Algorithms for Nickel and Lithium Battery Chargers. IEEE Trans. Veh. Technol. 2011, 60, 830-838. [CrossRef] 
33. Shen, W.; Vo, T.T.; Kapoor, A. Charging algorithms of lithium-ion batteries: An overview. In Proceedings of the 2012 7th IEEE Conference on Industrial Electronics and Applications (ICIEA), Singapore, 18-20 July 2012; pp. 1567-1572.

34. Hesse, H.C.; Schimpe, M.; Kucevic, D.; Jossen, A. Lithium-Ion Battery Storage for the Grid-A Review of Stationary Battery Storage System Design Tailored for Applications in Modern Power Grids. Energies 2017, 10, 2107. [CrossRef]

35. Analog Devices. Available online: http://www.analog.com/media/en/technical-documentation/technicalarticles / A-Closer-Look-at-State-Of-Charge-and-State-Health-Estimation-Techniques-....pdf (accessed on 1 February 2018).

36. Fathoni, G.; Widayat, S.A.; Topan, P.A.; Jalil, A.; Cahyadi, A.I.; Wahyunggoro, O. Comparison of State-of-Charge (SOC) estimation performance based on three popular methods: Coulomb counting, open circuit voltage, and Kalman filter. In Proceedings of the 2017 2nd International Conference on Automation, Cognitive Science, Optics, Micro Electro-Mechanical System, and Information Technology (ICACOMIT), Jakarta, Indonesia, 23-24 October 2017; pp. 70-74.

37. Lyu, C.; Cong, W.; Liu, H.; Zhang, L. A novel parameters acquisition method based on electrochemical impedance spectroscopy mathematical model in lithium ion cell. In Proceedings of the 2017 Prognostics and System Health Management Conference (PHM-Harbin), Harbin, China, 9-12 July 2017; pp. 1-8.

38. Hu, X.; Li, S.E.; Yang, Y. Advanced Machine Learning Approach for Lithium-Ion Battery State Estimation in Electric Vehicles. IEEE Trans. Transp. Electrification 2016, 2, 140-149. [CrossRef]

39. Piller, S.; Perrin, M.; Jossen, A. Methods for state-of-charge determination and their applications. J. Power Sources 2001, 96, 113-120. [CrossRef]

40. Kim, D.; Goh, T.; Park, M.; Kim, S.W. Fuzzy Sliding Mode Observer with Grey Prediction for the Estimation of the State-of-Charge of a Lithium-Ion Battery. Energies 2015, 8, 12409-12428. [CrossRef]

41. Tian, Y.; Li, D.; Tian, J.; Xia, B. State of charge estimation of lithium-ion batteries using an optimal adaptive gain nonlinear observer. Electrochim. Acta 2017, 225, 225-234. [CrossRef]

42. Rivera-Barrera, J.P.; Muñoz-Galeano, N.; Sarmiento-Maldonado, H.O. SoC Estimation for Lithium-ion Batteries: Review and Future Challenges. Electronics 2017, 6, 102. [CrossRef]

43. Kozlowski, J.D. Electrochemical Cell Prognostics Using Online Impedance Measurements and Model-Based Data Fusion Techniques. In Proceedings of the IEEE Aerospace Conference, Big Sky, MT, USA, 8-15 March 2003; Volume 7, pp. 3257-3270.

44. Xiong, R.; Cao, J.; Yu, Q.; He, H.; Sun, F. Critical Review on the Battery State of Charge Estimation Methods for Electric Vehicles. IEEE Access 2018, 6, 1832-1843. [CrossRef]

45. Lin, C.H.; Wang, C.-M.; Lin, W.-J. A SOC-based intelligent charger with multi-charging mode. In Proceedings of the 2015 IEEE 2nd International Future Energy Electronics Conference (IFEEC), Taipei, Taiwan, 1-4 November 2015; pp. 1-6.

46. Oliveira, T.R.; Gonçalves Silva, W.W.A.; Donoso-Garcia, P.F. Distributed Secondary Level Control for Energy Storage Management in DC Microgrids. IEEE Trans. Smart Grid 2017, 8, 2597-2607. [CrossRef]

47. Velho, R.; Beirão, M.; Calado, M.R.; Pombo, J.; Fermeiro, J.; Mariano, S. Management System for Large Li-Ion Battery Packs with a New Adaptive Multistage Charging Method. Energies 2017, 10, 605. [CrossRef]

48. Xue, F.; Ling, Z.; Yang, Y.; Miao, X. Design and Implementation of Novel Smart Battery Management System for FPGA Based Portable Electronic Devices. Energies 2017, 10, 264. [CrossRef]

49. Doan, V.T.; Vu, V.B.; Vu, H.N.; Tran, D.H.; Choi, W. Intelligent charger with online battery diagnosis function. In Proceedings of the 2015 9th International Conference on Power Electronics and ECCE Asia (ICPE-ECCE Asia), Seoul, Korea, 1-5 June 2015; pp. 1644-1649.

50. Diaz, J.; Martin-Ramos, J.A.; Pernia, A.M.; Nuno, F.; Linera, F.F. Intelligent and universal fast charger for $\mathrm{Ni}-\mathrm{Cd}$ and Ni-MH batteries in portable applications. IEEE Trans. Ind. Electron. 2004, 51, 857-863. [CrossRef]

51. Mundra, T.S.; Kumar, A. An Innovative Battery Charger for Safe Charging of NiMH/NiCd Batteries. IEEE Trans. Consum. Electron. 2007, 53, 1044-1052. [CrossRef]

52. Hu, X.; Martinez, C.M.; Yang, Y. Charging, Power management, and battery degradation mitigation in plug-in hybrid electric vehicles: A unified cost-optimal approach. Mech. Syst. Signal Process. 2017, 87, 4-16. [CrossRef] 
53. Yong, S.O.; Rahim, N.A. Development of on-off duty cycle control with zero computational algorithm for CC-CV Li ion battery charger. In Proceedings of the 2013 IEEE Conference on Clean Energy and Technology (CEAT), Lankgkawi, Malaysia, 18-20 November 2013; pp. 422-426.

54. Salas-Puente, R.; Marzal, S.; González-Medina, R.; Figueres, E.; Garcera, G. Experimental Study of a Centralized Control Strategy of a DC Microgrid Working in Grid Connected Mode. Energies 2017, 10, 1627. [CrossRef]

55. Monteiro, V.; Ferreira, J.C.; Melendez, A.A.; Couto, C.; Afonso, J.L. Experimental Validation of a Novel Architecture Based on a Dual-Stage Converter for Off-Board Fast Battery Chargers of Electric Vehicles. IEEE Trans. Veh. Technol. 2017, 67, 1000-1011. [CrossRef]

56. Bhatt, M.; Hurley, W.G.; Wolfle, W.H. A new approach to intermittent charging of valve-regulated lead-acid batteries in standby applications. IEEE Trans. Ind. Electron. 2005, 52, 1337-1342. [CrossRef]

57. Hussein, A.A.H.; Pepper, M.; Harb, A.; Batarseh, I. An efficient solar charging algorithm for different battery chemistries. In Proceedings of the 2009 IEEE Vehicle Power and Propulsion Conference, Dearborn, MI, USA, 7-10 September 2009; pp. 188-193.

58. Gallardo-Lozano, J.; Milanés-Montero, M.I.; Guerrero-Martínez, M.A.; Romero-Cadaval, E. Electric vehicle battery charger for smart grids. Electr. Power Syst. Res. 2012, 90, 18-29. [CrossRef]

59. López, J.; Seleme, S.I.; Donoso, P.F.; Morais, L.M.F.; Cortizo, P.C.; Severo, M.A. Digital control strategy for a buck converter operating as a battery charger for stand-alone photovoltaic systems. Sol. Energy 2016, 140, 171-187. [CrossRef]

60. Dragičević, T.; Guerrero, J.M.; Vasquez, J.C.; Škrlec, D. Supervisory Control of an Adaptive-Droop Regulated DC Microgrid with Battery Management Capability. IEEE Trans. Power Electron. 2014, 29, 695-706. [CrossRef]

61. Chen, M.; Rincon-Mora, G.A. Accurate electrical battery model capable of predicting runtime and I-V performance. IEEE Trans. Energy Convers. 2006, 21, 504-511. [CrossRef]

62. Support, T. Installation, Commissioning and Operation Handbook for Gel-Vrla-Batteries. 2003. Available online: http:/ / www.sonnenschein.org/PDF\%20files/GelHandbookPart2.pdf (accessed on 13 October 2017).

63. PSIM10.0; PowerSim: Rockville, Maryland, MD, USA, 2016.

(C) 2018 by the authors. Licensee MDPI, Basel, Switzerland. This article is an open access article distributed under the terms and conditions of the Creative Commons Attribution (CC BY) license (http:/ / creativecommons.org/licenses/by/4.0/). 